\title{
The genetic basis of music ability
}

\author{
Yi Ting Tan ${ }^{1 *}$, Gary E. McPherson ${ }^{1}$, Isabelle Peretz ${ }^{2}$, Samuel F. Berkovic ${ }^{3}$ and Sarah J. Wilson ${ }^{3,4}$ \\ ${ }^{1}$ Melbourne Conservatorium of Music, University of Melbourne, Parkville, VIC, Australia \\ 2 International Laboratory for Brain, Music and Sound Research and Department of Psychology, Université de Montréal, Montreal, QC, Canada \\ ${ }^{3}$ Department of Medicine, Epilepsy Research Centre, University of Melbourne, Heidelberg, VIC, Australia \\ ${ }^{4}$ Melbourne School of Psychological Sciences, University of Melbourne, Parkville, VIC, Australia
}

\section{Edited by:}

Eckart Altenmüller, University of

Music and Drama Hannover,

Germany

Reviewed by:

Thomas F. Münte, University of Magdeburg, Germany

Erin E. Hannon, University of

Nevada, Las Vegas, USA

*Correspondence:

Yi Ting Tan, Melbourne

Conservatorium of Music,

University of Melbourne, Gate 12,

Building 141, Royal Parade, Parkville, VIC 3010, Australia

e-mail: yitt@student.unimelb.edu.au
Music is an integral part of the cultural heritage of all known human societies, with the capacity for music perception and production present in most people. Researchers generally agree that both genetic and environmental factors contribute to the broader realization of music ability, with the degree of music aptitude varying, not only from individual to individual, but across various components of music ability within the same individual. While environmental factors influencing music development and expertise have been well investigated in the psychological and music literature, the interrogation of possible genetic influences has not progressed at the same rate. Recent advances in genetic research offer fertile ground for exploring the genetic basis of music ability. This paper begins with a brief overview of behavioral and molecular genetic approaches commonly used in human genetic analyses, and then critically reviews the key findings of genetic investigations of the components of music ability. Some promising and converging findings have emerged, with several loci on chromosome 4 implicated in singing and music perception, and certain loci on chromosome $8 \mathrm{q}$ implicated in absolute pitch and music perception. The gene AVPR1A on chromosome 12q has also been implicated in music perception, music memory, and music listening, whereas SLC6A4 on chromosome $17 q$ has been associated with music memory and choir participation. Replication of these results in alternate populations and with larger samples is warranted to confirm the findings. Through increased research efforts, a clearer picture of the genetic mechanisms underpinning music ability will hopefully emerge.

Keywords: music, music ability, music perception, music production, genetic, genome, review

\section{INTRODUCTION}

Music is ubiquitous in all known human cultures. The general capacity for human beings to perceive, produce, and enjoy music even in the absence of formal music training suggest that music may be "hardwired" in our genetic makeup. However, the diversity of music competency across individuals adds impetus to the long-standing debate of whether musicians are born or made.

Studies on the genetic basis of music ability have been relatively scarce, compared with more extensive investigation conducted in the language domain (for recent reviews of the genetic findings on speech and language, see Newbury and Monaco, 2010; CarrionCastillo et al., 2013; Graham and Fisher, 2013; Raskind et al., 2013; Szalontai and Csiszar, 2013). Moreover, the earlier behavioral genetic investigations of music ability often lacked scientific rigor or suffered from small sample sizes (see Coon and Carey, 1989 for examples). The advent of molecular genetics in the postgenomic era holds much promise for this relatively underexplored field.

Since the boom of molecular genetic research, the current state of knowledge of the genetic basis of music ability has not been reviewed. Thus, it is timely to consolidate behavioral and molecular genetic findings and provide a critical overview of what is currently known about the genetic basis of various music phenotypes. Current challenges and possible directions for future research are also considered. This review aims to facilitate a greater understanding of this relatively new field among music and genetics researchers, and encourage increased research effort into uncovering the genetic basis of music ability.

\section{HUMAN GENETIC METHODS: OVERVIEW}

The relationship between phenotypes and genes can be investigated through various genetic analytical approaches. In order to offer readers of diverse backgrounds a preliminary understanding, this section provides an introductory overview of the behavioral and molecular genetic approaches commonly used in human genetic analyses. A glossary of genetic terminology (terms shown in bold in the text) is also available as Supplementary Material online.

\section{BEHAVIORAL GENETIC APPROACHES Familial aggregation}

One of the first questions asked in human genetic analysis is whether a trait clusters in families above chance level. Familial aggregation can address this question by comparing whether the prevalence of a trait is higher within the family of a proband than that in the general population (Naj et al., 2012). This approach 
is non-invasive because only phenotypic information is gathered from the families and controls. One common measure arising from familial aggregation is the sibling recurrence-risk ratio $\left(\boldsymbol{\lambda}_{\boldsymbol{s}}\right)$, which determines the proportion of proband siblings also exhibiting the studied trait, relative to the population prevalence. The magnitude and patterns of familial correlations observed in familial aggregation studies can yield useful clues to the roles played by genes and the environment (Naj et al., 2012). While a $\lambda_{s}$ close to 1 suggests genetic influences are unimportant, higher values $(>5)$ indicate that a genetic hypothesis is worth pursuing (Mitry et al., 2011). A related measure is the sibling relative risk (sib RR), which is the ratio of the proband $\lambda_{s}$ to the control $\lambda_{s}$.

Familial aggregation measures such as $\lambda_{s}$ may be inflated by ascertainment bias (Guo, 1998). Moreover, familial aggregation only serves to determine the existence of familial clustering. It does not seek to explain how much of the familial clustering is due to genetic or environmental factors. Such questions can be addressed through follow-up studies, such as twin and adoption studies.

\section{Twin studies}

Twin studies take a step further by disentangling the relative contributions of genetic and environmental factors on trait variation (Verweij et al., 2012). Monozygotic (MZ) twins share 100\% of their genes whereas dizygotic (DZ) twins share on average 50\% of their genes. By comparing the similarity of the $M Z$ twin pairs on the trait of interest with that of the DZ twin pairs, greater similarity exhibited by $\mathrm{MZ}$ twin pairs indicates a possible genetic influence. In other words, if the concordance for a trait is much higher in the MZ twins, the trait is likely to have significant heritability.

Through twin studies, the effects of genetic influence, shared environment (family environment), and unique environment on a trait can be estimated through structural equation modeling using statistical programs such as $M x$ (Neale et al., 2006). Basic twin designs can be extended to allow multiple traits to be studied simultaneously or to analyze more complex genetic and environmental influences. For instance, additional family members can be incorporated into the design (Verweij et al., 2012).

There are some criticisms surrounding the validity of twin studies given that the twin design is built on a number of assumptions (Richardson and Norgate, 2005). For instance, the "equal environment" assumption presupposes that regardless of zygosity, all twins raised together experience equally similar shared environments. Some research, however, suggests that $\mathrm{MZ}$ twins may be treated more similarly than DZ twins (Plomin et al., 1976; but see Borkenau et al., 2002).

Besides twin studies, heritability can also be estimated from family pedigrees. Heritability in the narrow sense $\left(\boldsymbol{h}^{2}\right)$ is the ratio of the additive genetic variance to the total phenotypic variance of a trait. Since the magnitude of $h^{2}$ can indicate the statistical power for discovering the causal genes of a trait, heritability estimation serves as a good precursor to molecular genetic studies (Bochud, 2012). If the $h^{2}$ estimates of multiple related traits are available, the trait with the best $h^{2}$ estimate can be chosen for subsequent gene mapping. In human research, the general consensus is that $h^{2}$ estimates below 0.2 are considered low, those between 0.2 and 0.5 are moderate, and estimates above 0.5 indicate high heritability. High $h^{2}$ estimates suggest that the genotype is closely correlated with the trait phenotype, but it should be noted that this does not necessarily imply that every gene associated with the trait has a large effect on the phenotype (Visscher et al., 2008). Some limitations of heritability estimation include a lack of information on the mode of inheritance of the trait, and the possibility that $h^{2}$ estimates may vary across populations or with time. In large pedigrees, there may also be cohort effects across different generations living under different socioeconomic circumstances, which may confound the "equal environment" within the sample population (Bochud, 2012).

\section{Segregation analysis}

After estimating the heritability of a trait of interest, the mode of inheritance of the trait can be elucidated through segregation analysis. Different segregation models representing various inheritance patterns of the trait are fitted to the family data. Using maximum likelihood procedures, the genetic model of best fit (i.e., the inheritance pattern which best explains how the trait is transmitted down the family line) can be identified. An important measure from segregation analysis is the segregation ratio, which is the proportion of offspring who inherit the trait of interest from a parent (Strachan and Read, 1999). The expected segregation ratios for autosomal dominant inheritance and autosomal recessive inheritance are 0.5 and 0.25 , respectively. As these expected segregation ratios are for Mendelian traits, deviation from these values indicate that the trait of interest may have incomplete penetrance, be predisposed by several genes in different loci, or that it is determined by both genetic and environmental factors. For instance in a study by Theusch and Gitschier (2011), absolute pitch was reported to have a segregation ratio of 0.089 , which suggests that the trait is not inherited in a simple Mendelian fashion. Similar to familial aggregation, a potential problem with segregation analysis is ascertainment bias, which may inflate the segregation ratio (Strachan and Read, 1999; Nandram et al., 2011), however it is possible to statistically correct for this (Li and Mantel, 1968; Li et al., 1987; Yao and Tai, 2000; Nandram et al., 2011).

Segregation analysis often serves as a precursor to parametric linkage analysis, as the latter requires the inheritance pattern of the studied trait to be specified (Schnell and Sun, 2012).

\section{MOLECULAR GENETIC APPROACHES Linkage analysis}

Once the genetic basis of a trait has been established using some of the above-mentioned methods, the next step is to conduct linkage analysis to map the potential genetic loci predisposing the trait. Linkage analysis requires each family member of a large family, or of several family pedigrees to be genotyped, typically using singlenucleotide polymorphism (SNP) arrays. If a genetic locus is thought to predispose a trait, family members who share the same markers near this locus should exhibit greater trait resemblance compared to those who do not share the markers. Therefore, linkage analysis aims to identify the markers on the SNP array that are commonly present in participants within or across pedigrees 
who exhibit the trait of interest. It should be noted that the identified markers are not the actual genes predisposing a trait; they are merely known locations on the genome that are near the gene of interest (Carey, 2003a). "Linkage" is said to occur when two gene loci that are in close proximity on the same chromosome are inherited together. In other words, if a marker is commonly shared among family members exhibiting the trait of interest, this marker is likely to be in linkage with the actual locus of the trait.

There are two common approaches to estimate linkage. The non-parametric or model-free linkage analysis basically tests whether relatives exhibiting the trait of interest share more alleles than would be expected by chance (Xu et al., 2012). In contrast, parametric or model-based linkage analysis requires the specification of the mode of inheritance, as ascertained by segregation analysis. Linkage is then tested by comparing the probability of obtaining the current test data if a marker locus and the trait locus are linked, to the probability of obtaining the test data if the two loci are not linked (Schnell and Sun, 2012). The ratio of the two probabilities expressed on a logarithmic scale is known as the LOD score. LOD scores are computed across all markers for each pedigree and then summed across different pedigrees. A LOD score $\geq 3$ is typically considered significant evidence for linkage, as it indicates that the odds that the two loci are linked and inherited together are greater than 1000-1. Alternatively, a LOD score $\leq-2$ is considered significant evidence to reject linkage. In general, scores within the range of $-2<x<3$ are regarded as inconclusive evidence for linkage, with those between $2 \leq x<3$ warranting additional study.

Linkage analysis is very successful in identifying Mendelian traits with a simple mode of inheritance, such as Huntington's disease. It has been less effective for complex traits predisposed by multiple genes as each gene individually exerts only a small effect on the trait (Nsengimana and Bishop, 2012). Large sample sizes are therefore needed to obtain adequate statistical power to detect linkage. Statistical power can also be increased by performing multipoint analysis (i.e., using multiple markers simultaneously), allowing more precise identification of the trait locus (Lathrop et al., 1984).

As parametric linkage analysis requires the pattern of inheritance to be specified, misspecification of the genetic model may lead to loss of power (Schnell and Sun, 2012). While this potential problem can be alleviated by testing more than one genetic model, multiple-testing issues increase the likelihood of false positives (Weeks et al., 1990). A further shortcoming of linkage analysis is that the identified linkage region typically contains numerous genes. Fine-mapping of the linkage region is therefore necessary to narrow down the locus and determine the possible causative gene (Carey, 2003b). With the development of exome sequencing technologies (see below), fine-mapping is now less essential as all genes in the linkage region can be quickly analyzed.

\section{Association analysis}

Association analysis is a statistical method used to investigate the association between a genetic variant and a trait (Carey, 2003b). Association analysis can be used to test potential genetic variants that lie in significant linkage regions. It can also be employed when there are well-founded reasons to suspect a gene's involvement in predisposing a trait. An association analysis can either adopt a population-based design involving unrelated cases and controls, or a family-based design in which relatives of cases serve as controls for the study.

In the candidate gene approach, statistical tests are performed to determine if the cases have a higher frequency of a particular allelic variant of the candidate gene, as compared with the controls. The possible association between an allelic variant and the trait of interest may yield valuable information about the variant's role in the biological pathway of the trait. One major limitation of candidate gene studies is that only specific allelic variants are investigated; the success of an association study thus hinges on the accuracy of a researcher's "educated guess" of the potential candidate genes. Moreover, if the trait of interest is complex and multiple genes are involved, the candidate gene approach is not able to detect the influence of the predisposing genes in other loci.

By contrast, a genome-wide association study (GWAS) can be conducted without prior knowledge of potential candidate genes. It involves an "agnostic" or non-candidate driven search of the entire human genome, typically using SNP arrays with a large number of common SNP markers found throughout the genome (Sun and Dimitromanolakis, 2012). If certain SNPs have a higher incidence in the cases relative to the controls, this will indicate a possible association of these SNPs with the trait of interest.

GWAS is a useful approach to find novel candidate genes predisposing a trait of interest, especially if the biological pathway of the trait is not well-understood. It is also possible to identify multiple genetic contributors to a complex trait, even if each of these may be conferring only a small effect (Reich and Lander, 2001). The downside is that to identify such SNPs of low effect size, large sample sizes are needed to achieve adequate power (typically thousands or even tens of thousands of cases and controls) (Spencer et al., 2009). However, large sample sizes may give rise to confounding factors such as population stratification and cryptic relatedness that result in false positives (Nsengimana and Bishop, 2012). Moreover, GWAS does not identify complete genes; it only identifies the genomic regions possibly associated with the trait, which in some cases may not even have a protein-coding gene in the vicinity.

A common problem faced by both the candidate gene approach and GWAS is the minimal replication of significant results across association studies (Lewis and Knight, 2012). Researchers must therefore exercise caution and critically examine the validity of published association studies, and make prudent design decisions for their own association studies (Attia et al., 2009).

\section{Exome sequencing}

With the advancement of high-throughput next-generation sequencing (NGS) technologies, exome sequencing has emerged as a rapid and cost-effective method for human genetic analysis (Singleton, 2011). The exome is the portion of the genome containing protein-coding information and represents about $1.5 \%$ of the whole genome. Exome sequencing is based on the assumption 
that changes in exons may modify the function of proteins coded by exons, thereby leading to changes in the phenotype. By targeting the exome instead of the entire genome, exome sequencing presents a cost- and time-effective means to find possible genetic variants predisposing a trait. Exome sequencing uses sequence capture methods to selectively capture exons from a DNA sample and enrich the available information from each sample, before using high-throughput sequencing to identify coding variants in the exome (Ku et al., 2012).

Since the publication of the first proof-of-concept study which used exome sequencing to identify causal variants for a rare Mendelian disorder ( $\mathrm{Ng}$ et al., 2009), exome sequencing has shown much promise in discovering coding variants for both Mendelian and non-Mendelian traits (Singleton, 2011). Like GWAS, exome sequencing can be performed without the foreknowledge of potential candidate genes or genetic variants. Its usefulness has also been shown in the diagnosis of disorders characterized by genetic heterogeneity (Singleton, 2011). Another advantage of exome sequencing is that it can identify uncommon causal variants predisposing rare Mendelian traits, which cannot be identified through linkage studies due to inadequate study power (Singleton, 2011).

Ultimately, exome sequencing may become a valuable genetic screening and diagnostic tool, allowing robust diagnoses to be reached rapidly and cost-effectively (Ku et al., 2012). However, it has some limitations. For instance, some regions of interest in the exome are difficult to sequence with the current technology, and the large amount of sequencing data generated poses computational challenge for analysis. Moreover, exome sequencing is unable to detect large deletions or rearrangements in the genome, and there is a major risk of false positives due to difficulties determining the biological relevance of coding variants to the trait of interest.

\section{Copy number variation (CNV) analysis}

Copy number variants are structural variants ( $>1000$ base pairs) whose copy numbers deviate from those found in the human reference genome. Such variation in the genome (known as copy number variation) includes insertions, deletions, duplications, inversions and translocations (Wain et al., 2009). More than 300 known causal genes for diseases are found to overlap with CNVs (Sebat et al., 2004), highlighting the impact CNVs may exert on genetic mechanisms and phenotypic variation. Understanding the functional impact of $\mathrm{CNVs}$, therefore, offers a fruitful means of elucidating the genetic basis of complex phenotypes.

There are several approaches to CNV detection. Microarraybased CNV analysis techniques typically use SNP arrays or aCGH (array comparative genomic hybridization) platforms to detect copy number gains or losses in the test sample compared with a reference sample (Alkan et al., 2011). CNV detection can also be achieved through a sequencing-based approach.

$\mathrm{CNV}$ analysis has shown its utility in the diagnosis of syndromes with heterogeneous phenotypes (Coughlin et al., 2012). However, understanding the significance and effect of detected CNVs on a trait of interest remains challenging. In addition, microarray-based CNV analysis has a number of drawbacks.
Copy neutral alterations (such as inversions and translocations) that do not cause a change in the total amount of genetic material cannot be identified by the microarray-based approach, even though such alterations are potentially deleterious. The microarray-based approach is also less sensitive in detecting duplications than deletions.

Given the continued advancement in sequencing technologies, sequencing-based approaches are likely to supersede microarraybased CNV analysis. In time, the ability of NGS to detect various forms of genetic variants (including small insertions/deletions and copy neutral variants) will improve and the cost of massive parallel sequencing will become less expensive. Nevertheless, this approach has not yet reached maturity and standard protocols and measures for sequencing-based CNV analysis have not been established. Moreover, the bioinformatics infrastructure, support, and cost required for managing, analyzing, and storing large amounts of sequencing data need to be carefully considered (Teo et al., 2012). In addition, the relatively short read lengths of NGS pose mapping issues in aligning the sequenced reads with the reference genome, especially in the duplicated regions of the genome. Thus, as with a microarray-based approach, copy number duplications remain less detectable than deletions with the sequencingbased method. Longer read lengths afforded by improvements in sequencing technology will potentially mitigate this issue.

\section{SCOPE OF THE REVIEW}

Indexed searches were performed in Scopus by searching for the following keywords: music* and (gene or genetic or genome or heritability or hereditary or innate) in the keyword field. Terms such as music therapy, algorithm, dystonia, musicola, animal, bird, and songbird were excluded. Subject areas such as computer science, engineering, health professions, physics and astronomy, mathematics, nursing and business, management and accounting were also excluded. Only papers published in English between 1988 and 2014 were considered since earlier genetic studies were often fraught with methodological limitations, such as small sample sizes and lack of scientific rigor. Based on these criteria the search identified 97 articles that were then manually canvassed to select those directly addressing the genetic bases of various aspects of music ability using behavioral genetic or molecular genetic methods. In addition, the reference section of each article was examined to identify additional studies not captured in the initial search. In total, this process identified 21 papers included in this review.

\section{SUMMARY OF THE REVIEW FINDINGS}

Table 1 shows the various music traits investigated and the number of genetic studies conducted on each trait to date. It indicates that the majority of studies have focused on music perception abilities (74\%), of which absolute pitch has been most extensively investigated (39\%). In light of this, findings pertaining to music perception abilities are examined first, followed by those relating to music production abilities. Tables 2,3 that follow provide a more detailed summary of the genetic findings from behavioral and molecular studies, respectively. 
Table 1 | The number of genetic studies investigating various music traits.

\begin{tabular}{|c|c|c|c|}
\hline \multicolumn{2}{|l|}{ Music trait } & \multirow{2}{*}{$\begin{array}{c}\text { Studies } \\
9\end{array}$} & \multirow{2}{*}{$\begin{array}{l}\text { Authors } \\
\text { Profita and Bidder, 1988; } \\
\text { Gregersen and Kumar, 1996; } \\
\text { Baharloo et al., 1998, 2000; } \\
\text { Gregersen et al., 1999, 2001, } \\
\text { 2013; Theusch et al., 2009; } \\
\text { Theusch and Gitschier, } 2011\end{array}$} \\
\hline $\begin{array}{l}\text { Music } \\
\text { perception }\end{array}$ & $\begin{array}{l}\text { Absolute } \\
\text { pitch }\end{array}$ & & \\
\hline & $\begin{array}{l}\text { Congenital } \\
\text { amusia }\end{array}$ & 1 & Peretz et al., 2007 \\
\hline & $\begin{array}{l}\text { Music } \\
\text { perception } \\
\text { (in general) }\end{array}$ & 5 & $\begin{array}{l}\text { Drayna et al., 2001; Pulli et al., } \\
\text { 2008; Ukkola et al., 2009; } \\
\text { Ukkola-Vuoti et al., 2013; } \\
\text { Oikkonen et al., } 2014\end{array}$ \\
\hline & $\begin{array}{l}\text { Melodic } \\
\text { memory }\end{array}$ & 1 & Granot et al., 2007 \\
\hline & $\begin{array}{l}\text { Music } \\
\text { listening }\end{array}$ & 1 & Ukkola-Vuoti et al., 2011 \\
\hline \multirow[t]{3}{*}{$\begin{array}{l}\text { Music } \\
\text { production }\end{array}$} & $\begin{array}{l}\text { Singing } \\
\text { accuracy }\end{array}$ & 1 & Park et al., 2012 \\
\hline & $\begin{array}{l}\text { Singing } \\
\text { participation }\end{array}$ & 2 & $\begin{array}{l}\text { Coon and Carey, 1989; Morley } \\
\text { et al., } 2012\end{array}$ \\
\hline & $\begin{array}{l}\text { Music } \\
\text { creativity }\end{array}$ & 2 & $\begin{array}{l}\text { Ukkola et al., 2009; } \\
\text { Ukkola-Vuoti et al., } 2013\end{array}$ \\
\hline Self-reportec & usic ability & 1 & Vinkhuyzen et al., 2009 \\
\hline
\end{tabular}

\section{MUSIC PERCEPTION ABILITIES \\ Absolute pitch ability}

Absolute pitch (AP) or "perfect pitch" is the rare music ability of being able to identify or produce pitches without relying on an external reference. It has an estimated prevalence of less than 1 in 10,000 (Bachem, 1955; Profita and Bidder, 1988). While AP is neither a prerequisite nor a predictor for outstanding musicianship, its rarity and the musical advantages it confers have generated much research interest into its etiology.

Several studies have explored the genetic basis of AP through family studies. One of the earliest was a segregation study conducted by Profita and Bidder (1988), who reported significant familial incidence in 35 AP probands from 19 families. AP was more common in females of this sample, and vertical transmission was commonly observed. The segregation ratio was estimated to lie between 0.24 and 0.37 , suggesting a possible autosomal dominant gene with incomplete penetrance. Recurrence risk ratios could not be determined because the study did not recruit any control participants.

A subsequent familial aggregation study yielded a sibling recurrence risk-ratio $\left(\lambda_{\mathrm{s}}\right)$ estimate of 20 , meaning that siblings of AP possessors are approximately 20 times more likely to possess AP relative to the general population (Gregersen and Kumar, 1996). Gregersen's team subsequently conducted another two familial aggregation studies and obtained sibling relative risk (sib
RR) estimates of 8.3 and 12.2, respectively (Gregersen et al., 1999, 2001). This measure indicates that the siblings of the AP possessors were 8.3 and 12.2 times more likely to have AP compared to the siblings of the controls. Sib RR generally provides a more conservative measure than $\lambda_{s}$ (Naj et al., 2012), likely accounting for the lower sib RR values. As noted in the previous section, familial aggregation does not distinguish between genetic and environmental contributions to a trait, making it possible that the high familial aggregation estimates stem from environmental influences such as early music training, which has been identified as a key environmental determinant of AP (Sergeant, 1969; Miyazaki, 1988; Profita and Bidder, 1988; Gregersen et al., 2007; Wilson et al., 2012).

In view of this, Baharloo et al. (1998) controlled for early music training by only analyzing families where the participants and one or more of their siblings had received music training before 6 years of age. The $\lambda_{\mathrm{s}}$ was estimated to be approximately 7.5 (Gregersen, 1998). In a subsequent study, Baharloo and colleagues estimated $\lambda_{s}$ for the most stringent form of AP, termed "AP-1" (Baharloo et al., 2000). The AP-1 phenotype was characterized by a consistently high level of pitch naming ability, falling at least three standard errors above the mean score of a randomized group of AP and non-AP musicians. Also controlling for early music training, the $\lambda_{\mathrm{s}}$ for AP-1 was estimated to fall within 7.8-15.1, with a greater likelihood of the true value being found near the upper end of this range. It is possible, however, that even after controlling for early music training, the estimated $\lambda_{s}$ may still be influenced by other shared environmental factors experienced by the AP-1 probands and their concordant siblings. The authors therefore noted that the $\lambda_{s}$ estimate may not entirely reflect genetic factors. Nonetheless, the high estimates of $\lambda_{s}$ from various familial aggregation studies suggest a major role for genetic influences on the development of AP and the possibility of a major-gene effect.

More recently, evidence suggests that multiple genetic factors may be involved in the etiology of AP (Theusch and Gitschier, 2011). A segregation analysis performed on 1463 AP-1 probands yielded a segregation ratio of 0.089 , which is considerably lower than the estimate from the small AP sample in Profita and Bidder (1988) and the segregation ratios of 0.25 and 0.5 for autosomal recessive and autosomal dominant inheritance, respectively. This suggests that AP was not inherited in a simple Mendelian fashion, however, genetic factors likely play a role since within this larger sample, 11 out of $14 \mathrm{MZ}$ twin pairs were concordant for AP-1 in comparison to only 14 out of $31 \mathrm{DZ}$ twin pairs. These results yielded a significantly different casewise concordance rate of 78.6 and $45.2 \%$, respectively.

Other supporting evidence for a genetic basis for AP comes from ethnicity effects observed in music students. Gregersen et al. (2001) reported that Chinese, Korean and Japanese music theory students had a substantially higher incidence of AP (47.5\%) compared to Caucasian students $(9 \%)$. Although some researchers have attributed this "Asian advantage" to environmental factors, such as early tone-language exposure (Henthorn and Deutsch, 2007), this does not fully account for the higher incidence of AP among all Asian ethnic subgroups since essentially, Korean and Japanese are not tone languages (Sohn, 1999; Zatorre, 2003; 
Table 2 | Summary of behavioral genetic studies investigating various music traits.

\begin{tabular}{|c|c|c|c|}
\hline Trait & Type of study & Participants & Findings \\
\hline & $\begin{array}{l}\text { Familial aggregation } \\
\text { (Baharloo et al., 1998) }\end{array}$ & $\begin{array}{l}92 \text { self-reported AP probands } \\
520 \text { non-AP probands }\end{array}$ & $\begin{array}{l}\lambda_{s}: \sim 7.5 \\
\text { (controlled for early music training) }\end{array}$ \\
\hline & $\begin{array}{l}\text { Familial aggregation } \\
\text { (Gregersen et al., 1999) }\end{array}$ & 2707 tertiary music students & Sib RR: $\sim 8.3$ \\
\hline & $\begin{array}{l}\text { Familial aggregation } \\
\text { (Baharloo et al., 2000) }\end{array}$ & $\begin{array}{l}74 \text { AP- } 1 \text { probands with } 113 \text { siblings } \\
625 \text { controls }\end{array}$ & $\begin{array}{l}\lambda_{s}: 7.8-15.1 \\
\text { (controlled for early music training) }\end{array}$ \\
\hline & $\begin{array}{l}\text { Twin study } \\
\text { (Theusch and Gitschier, 2011) }\end{array}$ & $14 \mathrm{MZ}$ and $31 \mathrm{DZ}$ female twin pairs & $\mathrm{CCR}_{\mathrm{MZ}}: 78.6 \% ; \mathrm{CCR}_{\mathrm{DZ}}: 45.2 \%$ \\
\hline Congenital amusia & $\begin{array}{l}\text { Familial aggregation } \\
\text { (Peretz et al., 2007) }\end{array}$ & $\begin{array}{l}13 \text { probands, } 58 \text { family members } \\
\text { (9 families) } \\
17 \text { controls, } 58 \text { family members } \\
\text { (10 families) }\end{array}$ & $\begin{array}{l}\lambda_{s}: 10.8 \\
\lambda_{0}: 2.3\end{array}$ \\
\hline $\begin{array}{l}\text { Melodic perception } \\
\text { (tune recognition) }\end{array}$ & $\begin{array}{l}\text { Twin study } \\
\text { (Drayna et al., 2001) }\end{array}$ & $136 \mathrm{MZ}$ and $148 \mathrm{DZ}$ twin pairs & A: $71-80 \% ; C: 0 \% ; E: 20-29 \%$ \\
\hline $\begin{array}{l}\text { Singing } \\
\text { (pitch accuracy) }\end{array}$ & $\begin{array}{l}\text { Pedigree study } \\
\text { (Park et al., 2012) }\end{array}$ & 73 extended families $(N=1008)$ & Heritability: $40 \%$ \\
\hline $\begin{array}{l}\text { Participation in singing } \\
\text { activities }\end{array}$ & $\begin{array}{l}\text { Twin study } \\
\text { (Coon and Carey, 1989) }\end{array}$ & $\begin{array}{l}850 \text { twin pairs } \\
\text { (from Loehlin and Nichols, 1976) }\end{array}$ & $\begin{array}{l}\text { A: } 71 \% \text { (males) \& } 20 \% \text { (females); } \\
\text { C: } 8 \% \text { (males) \& 59\% (females) }\end{array}$ \\
\hline Music creativity & $\begin{array}{l}\text { Pedigree study } \\
\text { (Ukkola et al., 2009) }\end{array}$ & 19 Finnish musical families ( $N=343$ ) & $\begin{array}{l}\text { Heritability for music creativity: } 84 \% \\
\text { (Composing: } 40 \% \text {; Arranging: } 46 \% \text {; } \\
\text { Improvising: } 62 \% \text { ) }\end{array}$ \\
\hline \multirow[t]{2}{*}{$\begin{array}{l}\text { Self-reported music } \\
\text { ability }\end{array}$} & $\begin{array}{l}\text { Twin study } \\
\text { (Coon and Carey, 1989) }\end{array}$ & $\begin{array}{l}850 \text { twin pairs } \\
\text { (from Loehlin and Nichols, 1976) }\end{array}$ & $\begin{array}{l}\text { Out-of-school music performances: } \\
\text { A: } 38 \% \text { (males) \& 10\% (females); } \\
\text { C: } 18 \% \text { (males) \& } 63 \% \text { (females) }\end{array}$ \\
\hline & $\begin{array}{l}\text { Twin study } \\
\text { (Vinkhuyzen et al., 2009) }\end{array}$ & $\begin{array}{l}1685 \text { Netherlands twin pairs } \\
(12-24 \text { years) }\end{array}$ & $\begin{array}{l}\text { Musical aptitude: } \\
\text { A: } 66 \% ; C: 8 \% ; E: 25 \% \text { (males) } \\
\text { A: } 30 \% ; C: 54 \% ; E: 16 \% \text { (females) } \\
\text { Exceptional musical talent: } \\
\text { A: } 92 \% ; C: 0 \% ; E: 8 \%\end{array}$ \\
\hline
\end{tabular}

$\lambda_{s}$, sibling recurrence risk; $\lambda_{0}$, offspring recurrence risk; $C C R_{M Z}$, casewise concordance rate for $M Z$ twins; $C C R_{D Z}$, casewise concordance rate for $D Z$ twins; $C O M B$, Combined music aptitude (SP+ST+KMT) score; A, additive genetic variance (heritability); $C$, common/shared environmental variance; $E$, unique environmental variance; KMT, Karma music test; SP, Seashore's pitch discrimination test; ST, Seashore's time discrimination test; Sib RR, sibling relative risk; SR, segregation ratio. 
Table 3 | Summary of molecular genetic studies investigating various music traits.

\begin{tabular}{|c|c|c|c|c|c|c|c|}
\hline Trait & Study type & Participants & Ancestry & Locus implicated & $\begin{array}{l}\text { Genetic variant(s) } \\
\text { implicated }\end{array}$ & $\begin{array}{l}\text { Gene } \\
\text { impli- } \\
\text { cated }\end{array}$ & $\begin{array}{l}\text { Possible function(s) of } \\
\text { the gene }\end{array}$ \\
\hline & \multirow{2}{*}{$\begin{array}{l}\text { Genome-wide linkage } \\
\text { study } \\
\text { (Theusch et al., 2009) }\end{array}$} & \multirow{2}{*}{73 AP families* } & \multirow{2}{*}{$\begin{array}{l}\text { European, } \\
\text { Ashkenazi } \\
\text { Jewish, } \\
\text { Indian, } \\
\text { East } \\
\text { Asian }\end{array}$} & $7 q 22.3$ & $\begin{array}{l}\text { SNP rs2028030 } \\
\text { LOD }=2.074 \mathrm{Eu} \\
\text { LOD 1-1.5 E Asian }\end{array}$ & & \\
\hline & & & & $8 q 21.11$ & $\begin{array}{l}\text { SNP rs } 1007750 \\
\mathrm{LOD}=2.069 \mathrm{Eu} / \mathrm{AJ} / \mathrm{l} \\
\mathrm{LOD}=2.236 \text { for } \mathrm{Eu}\end{array}$ & & \\
\hline
\end{tabular}

Genome-wide linkage 53 AP multiplex Caucasian, 6q14.1-16.1

study; exome sequencing families, $\quad$ Asian $\quad$ Peak $L O D=4.68$

(Gregersen et al., 2013) 36 synaesthesia

multiplex

families
EPHA7 Neural connectivity and development

\begin{tabular}{ll}
\hline $2 \mathrm{q}$ & SNP rs1482308 \\
& HLOD $=4.7$ \\
& (combined data set) \\
& SNP rs6759330 \\
& HLOD $=3.93$ \\
& (AP families)
\end{tabular}

Perception Genome-wide linkage

of pitch study

and (Pulli et al., 2008)

rhythm

15 musica
families
$(N=234)$

15 musical

Finnish

$4 q 22$

$(N=234)$
Near markers D4S423 and D4S2460 $\mathrm{LOD}=3.33$
UNC5C Netrin receptor. Netrins direct axon extension and cell migration during neural development

8q13-21

$\mathrm{LOD}=2.29$

TRPA1 Implicated in the hair cell transduction channel of the inner ear

\section{Candidate gene} 19 musical
RS1 + RS3 haplotype (corrected $p<0.001$ for $\mathrm{KMT}$ and $\mathrm{COMB}$ ) association study

Finnish

$12 q 14.2$ families

(Ukkola et al., 2009)

$(N=343)$

Genome-wide CNV

analysis 5 extended families,

(Ukkola-Vuoti et al., 2013)

172 unrelated individuals

AVPR1A Social cognition and behavior; spatial memory

Pcdha 1-9 Neural migration, differentiation and synaptogenesis; learning and memory

(linked to low

COMB)

Learning and memory

Duplication on

8q24.22 (linked to

low COMB)

Genome-wide linkage

and association study

(Oikkonen et al., 2014)

76 families $\quad$ Finnish
$(N=767)$

SNP rs9854612 (PPLD $=$ GATA2 0.98 for $\mathrm{COMB}$ )

4p15-q24 (linked to SP, ST, KMT, COMB)

SNP rs13146789 \& SNP PCDH7

rs13109270

(PPLD $=0.81$ for $\mathrm{COMB}$ )
ADCY8 Learning and memory

Development of cochlear hair cells and the inferior colliculus

Expressed in cochlea (chicken) \& amygdala (mice) 


\section{Table 3 | Continued}

\begin{tabular}{|c|c|c|c|c|c|c|c|}
\hline Trait & Study type & Participants & Ancestry & Locus implicated & $\begin{array}{l}\text { Genetic variant(s) } \\
\text { implicated }\end{array}$ & $\begin{array}{l}\text { Gene } \\
\text { impli- } \\
\text { cated }\end{array}$ & $\begin{array}{l}\text { Possible function(s) of } \\
\text { the gene }\end{array}$ \\
\hline $\begin{array}{l}\text { Music } \\
\text { listening }\end{array}$ & $\begin{array}{l}\text { Candidate gene } \\
\text { association study } \\
\text { (Ukkola-Vuoti et al., 2011) }\end{array}$ & $\begin{array}{l}31 \text { families } \\
(N=437)\end{array}$ & Finnish & $12 q 14.2$ & $\begin{array}{l}\text { RS1+AVR haplotype: } \\
\text { current active music } \\
\text { listening ( } p=0.0019 \text { ); } \\
\text { RS1+RS3 haplotype: } \\
\text { lifelong active music } \\
\text { listening ( } p=0.0022 \text { ) }\end{array}$ & AVPR1A & $\begin{array}{l}\text { Social cognition and } \\
\text { behavior; spatial } \\
\text { memory }\end{array}$ \\
\hline \multirow{3}{*}{$\begin{array}{l}\text { Singing } \\
\text { (pitch } \\
\text { accuracy) }\end{array}$} & \multirow{3}{*}{$\begin{array}{l}\text { Genome-wide linkage } \\
\text { and association study; } \\
\text { exome sequencing; CNV } \\
\text { analysis (Park et al., 2012) }\end{array}$} & \multirow[t]{3}{*}{$\begin{array}{l}73 \text { families } \\
(N=1008)\end{array}$} & \multirow[t]{3}{*}{ Mongolian } & $4 q 23$ & $\begin{array}{l}\text { Marker D4S2986 } \\
\text { LOD }=3.1\end{array}$ & & \\
\hline & & & & $4 q 26$ & $\begin{array}{l}\text { SNP rs12510781 } \\
\left(p=8.4 \times 10^{-17}\right) \\
\text { SNP rs4148254 } \\
\left(p=8.0 \times 10^{-17}\right)\end{array}$ & UGT8 & $\begin{array}{l}\text { Catalyzes the transfer } \\
\text { of galactose to } \\
\text { ceramide }\end{array}$ \\
\hline & & & & $\begin{array}{l}\text { Deletion at } 5.6 \mathrm{~kb} \\
\text { upstream of UGT8 } \\
\text { (linked to low pitch } \\
\text { accuracy) }\end{array}$ & & & \\
\hline \multirow{2}{*}{$\begin{array}{l}\text { Music } \\
\text { creativity }\end{array}$} & \multirow{2}{*}{$\begin{array}{l}\text { Genome-wide CNV } \\
\text { analysis } \\
\text { (Ukkola-Vuoti et al., 2013) }\end{array}$} & \multirow{2}{*}{$\begin{array}{l}5 \text { extended } \\
\text { families, } \\
172 \text { unrelated } \\
\text { individuals }\end{array}$} & \multirow{2}{*}{ Finnish } & $\begin{array}{l}\text { Duplication on } \\
2 \mathrm{p} 22.1 \\
\text { (creative } \\
\text { phenotype) }\end{array}$ & & GALM & $\begin{array}{l}\text { Associated with } \\
\text { serotonin transporter } \\
\text { binding potential in } \\
\text { human thalamus, which } \\
\text { is implicated in music } \\
\text { perception }\end{array}$ \\
\hline & & & & $\begin{array}{l}\text { Deletion on } 2 \mathrm{p} 12 \text {, } \\
3 \mathrm{p} 14.1,3 \mathrm{q} 28 \\
\text { (non-creative } \\
\text { phenotype) }\end{array}$ & & & \\
\hline
\end{tabular}

*Families with at least two AP possessors who were not simply a parent-child relative pair.

ADCY8, adenylate cyclase 8; AJ, Ashkenazi Jewish ancestry; AVPR1A, arginine vasopressin receptor 1A; CNV, copy number variation; COMB, Combined music aptitude (SP+ST+KMT) score; E Asian, East Asian ancestry; EPHA7, ephrin type-A receptor 7; Eu, European ancestry; GALM, galactose mutarotase (aldose 1epimerase); GATA2, GATA binding protein 2; HLOD, heterogeneity logarithm of odds score; I, Indian ancestry; KMT, Karma Music Test; LOD, logarithm of odds score; PCDH7, protocadherin 7; PCdha 1-9, protocadherin alpha 1 to 9; PPLD, posterior probability of linkage disequilibrium; SLC6A4, solute carrier family 6 (neurotransmitter transporter, serotonin), member 4; SNP, single nucleotide polymorphism; SP, Seashore's pitch discrimination test; ST, Seashore's time discrimination test; TRPA1, transient receptor potential cation channel, subfamily A, member 1; UGT8, uridine diphosphate glycosyltransferase 8; UNC5C, UNC-5 homolog C (C. elegans); ZDHHC11, zinc finger, DHHC-type containing 11. 
Kubozono, 2012). Further analysis of Gregersen's et al. (2001) study data revealed that the age of onset of music training and exposure to a "fixed do" training method before the age of 7 were the only strong predictors of AP acquisition in this sample (Gregersen et al., 2007).

Possible ethnicity effects for AP can also be observed from a genome-wide linkage study of 73 families of European, East Asian, Ashkenazi Jewish and Indian descent (Theusch et al., 2009) in the United States and Canada. In each family there were at least two AP possessors, not limited to a parent-child relative pair. Non-parametric multipoint linkage analyses were suggestive of linkage on chromosomes 8q24.21 $(\mathrm{LOD}=2.330)$ and $8 \mathrm{q} 21.11$ $(\mathrm{LOD}=2.069)$ for the European/Ashkenazi Jewish/Indian combined dataset (Table 3). Notably, one of the four genes found near the linkage peak on 8q24.21 was ADCY8 (adenylate cyclase 8), which is expressed almost exclusively in the brain and is implicated in learning and memory processes (Wong et al., 1999; Ludwig and Seuwen, 2002; De Quervain and Papassotiropoulos, 2006). When only the subset of 45 AP families of European descent was examined, there was strong evidence of linkage on chromosome 8q24.21 ( $\mathrm{LOD}=3.464$ at SNP rs3057), suggesting that at least one gene within this linkage region could predispose AP in individuals of European descent. A number of other linkage peaks were found in the European families, namely on loci 8q21.11 ( $\mathrm{LOD}=2.236), 7 \mathrm{q} 22.3(\mathrm{LOD}=2.074)$ and 9p21.3 $(\mathrm{LOD}=2.048)$. These peaks suggest that different genetic factors may underpin the etiology of AP, even within the same population. The linkage region on 7q22.3 was also observed in a subset of 19 AP families of East Asian ancestry, albeit with a smaller linkage peak (LOD approximately between 1 and 1.5). These findings support a strong genetic contribution to AP, which is likely to be heterogeneous. In other words, AP may be predisposed by different genetic variants at different chromosomal regions, both within and across populations of different ancestries.

A recently published study investigated the genetic relationship between AP and synaesthesia through a combined genome-wide linkage analysis of 53 multiplex families with AP (i.e., families in which multiple family members have AP) and 36 multiplex families with synaesthesia (Gregersen et al., 2013). Interestingly, 28 of the 126 AP possessors from the AP families reported synaesthesia, while eight synaesthesia families had a member with AP. Separate non-parametric linkage analysis of the AP and synaesthesia datasets revealed overlaps in several linkage regions (LOD > 2), especially on chromosomes 2 and 6. Given this overlap and the hypothesis that the two phenotypes may be jointly influenced by genes underpinning brain structural and functional connectivity, the researchers combined the AP and synaesthesia datasets for analysis. This revealed significant linkage on chromosome 6q14.1-6q16.1 (LOD $=4.68)$, where notably, a small linkage peak ( $\mathrm{LOD}=1.72)$ had been reported for the subset of 45 AP families of European ancestry studied by Theusch et al. (2009). Upon sequencing several potential candidate genes in this region, Gregersen et al. found that AP possessors from four of the AP multiplex families shared one or more of three non-synonymous variants of the gene EPHA7 (Ephrin type-A receptor 7). EPHA7 has been implicated in brain development, particularly establishing neural connectivity between auditory cortex and other cortical regions with the thalamus (North et al., 2013; Torii et al., 2013). Since neuroimaging studies have reported that both AP and synaesthesia are marked by atypical structural and functional connectivity (Rouw and Scholte, 2007; Loui et al., 2011; Dovern et al., 2012), it is conceivable that EPHA7 variants may influence these two phenotypes. More research involving extensive resequencing on the EPHA7 gene is needed in order to confirm its involvement. Using parametric linkage analysis, a more complex pattern of linkage was also observed on chromosome 2 in the combined AP and synaesthesia dataset, with a heterogeneity LOD score of 4.7 at SNP rs1482308. When only the AP families were considered, a maximum heterogeneity LOD score of 3.93 was observed at SNP rs6759330 on chromosome 2.

Inherent neuroanatomical differences between AP and nonAP possessors may also be genetically influenced. AP possessors show increased leftward asymmetry of the planum temporale (PT) due to a significantly smaller right mean PT volume compared with non-AP possessors (Keenan et al., 2001; Wilson et al., 2009). Keenan et al. (2001) suggested that the "pruning" of the right PT may be prenatally determined rather than due to early music training, since non-AP musicians with early music training do not manifest similar asymmetry. Wilson et al. (2009) subsequently demonstrated a striking difference in the right mean PT volumes of musicians with AP and quasi-absolute pitch (participants who scored between 20 and $90 \%$ on a note-naming test), even though the age of onset of music training did not differ significantly between these groups. Other supporting evidence comes from the discovery of an adult AP possessor, R.M., who had minimal music training but was able to perform a pitch memory task at a level indistinguishable from AP musicians. This case indicates that an early onset of music training (or any music training) may not be essential for AP to emerge (Ross et al., 2003), suggesting that AP and non-AP possessors may be using different pitch processing mechanisms (McLachlan et al., 2013b) that in part, reflect genetically influenced neuroanatomical differences.

\section{Congenital amusia}

Congenital amusia (commonly known as "tone deafness") is a fine-grained pitch perception deficit characterized by the inability to detect "wrong" notes in melodies, despite normal intellect, language and hearing abilities (Peretz and Hyde, 2003). Congenital amusia is uncommon in the general population, with an estimated population prevalence of 4\% (Kalmus and Fry, 1980). While the neurological basis of congenital amusia has been wellinvestigated (Peretz and Hyde, 2003; Hyde et al., 2007; Mandell et al., 2007; Loui et al., 2009; Mignault Goulet et al., 2012), few studies have explored its genetic basis.

In the first familial aggregation study on congenital amusia, Peretz et al. (2007) administered an online amusic diagnostic test to 13 amusic probands and 17 controls, as well as 58 family members of the probands (from 9 large families) and 58 family members of the controls (from 10 families). The results showed that $39 \%$ of first-degree relatives have congenital amusia, whereas only $3 \%$ of controls were similarly diagnosed. Notably, the $\lambda_{s}$ for congenital amusia was 10.8 , whereas the offspring recurrence risk was much lower at 2.3. While the high $\lambda_{\mathrm{s}}$ suggests a probable genetic basis for congenital amusia, Peretz et al. speculated 
that exposure to an enriched musical environment may mitigate the risk for offspring of amusic probands. However, Mignault Goulet et al. (2012) reported that after four weeks of daily music listening, the music perception scores and electrophysiological measures of seven amusic children (aged 10-12 years) did not vary essentially. This suggests that daily music listening is insufficient to improve pitch perception performance or stimulate neural plasticity in amusic children.

\section{Music perception: pitch, rhythm and sound patterns}

While music training may be necessary to develop specific music skills, there exists a "commonplace musical competence" that is possessed or easily acquired by most (Trehub, 2003). Investigations of infant musical behavior have shown that infants are capable of detecting melodic or rhythmic changes in musical patterns, as well as perceiving changes in pitch and rhythm (Trehub et al., 1984, 1987, 1999; Trainor and Trehub, 1992, 1993; Zentner and Kagan, 1996; Trainor and Heinmiller, 1998; Trainor et al., 2002; Trehub, 2006; He and Trainor, 2009) (Honing et al., 2009; Winkler et al., 2009). Coupled with the ubiquity of music across all cultures (McDermott and Hauser, 2005), these findings suggest that all humans are endowed with an intrinsic form of musicality, and that genetic factors may play a role in its manifestation.

In particular, individual differences in the ease of auditory skill acquisition point to predisposed differences in auditory ability. In one study, participants were classified as slow or fast learners in an auditory discrimination training task. Differences in behavioral performance were reflected in differential patterns of training-induced functional activation between the two groups (Gaab et al., 2006). Compared with the slow learners, fast learners recruited the left supramarginal gyrus and left Heschl's gyrus to a greater extent during the post-training phase. Jäncke et al. (2001) obtained similar findings, with different short-term functional activation patterns for participants who improved at a frequency discrimination task compared to those who showed no improvement. Likewise, Zatorre et al. (2012) found that participants who learned a micromelody task more quickly had steeper fMRI BOLD responses to pitch changes in their auditory cortex, even before they trained on the task. These findings suggest that predisposed differences in brain functioning may influence an individual's music perception abilities and the capacity to acquire musical skills.

Relative pitch (RP) perception may also be genetically influenced, as inferred from an ethnicity study by Hove et al. (2010). These researchers examined the RP ability of secondary school students with minimal music background using an interval identification task. Students from China or Taiwan (mean score $=72 \%$ ) significantly outperformed Caucasian (mean score $=$ 45.5\%) and Hmong students (mean score $=45.5 \%$ ), even though both Mandarin and Hmong are tonal languages. The researchers then conducted a similar study with Caucasian, Chinese, and Korean undergraduates with minimal music training (Hove et al., 2010). The Chinese (mean score $=72.2 \%$ ) and Korean students (mean score $=78.2 \%$ ) significantly outperformed the Caucasian students (mean score $=58.2 \%$ ) but performed similarly to each other. Interestingly, these ethnicity effects only occurred in the pitch domain with no differences observed on a rhythm-pattern task. Moreover, as most of the Korean participants spoke Seoul or standard South Korean, both of which are non-pitch-accented (Sohn, 1999), it is unlikely that the ethnicity effects stemmed from tone-language experience. Neither the degree of tone-language experience (fluent or non-fluent), the primary language spoken at home (tonal or non-tonal), nor time spent in East Asia during early childhood were associated with RP ability of the East Asian participants. It is therefore possible that the ethnicity effects observed for RP processing have a genetic basis.

Foster and Zatorre (2010) observed that gray matter volume and cortical thickness in the right Heschl's sulcus and bilateral intraparietal sulcus predicted performance on a relative pitch task, even after accounting for music training. As significant heritabilities (65-97\%) for overall brain volume and gray and white-matter volumes have been consistently documented across behavioral genetics research (Peper et al., 2007), these findings are consistent with genetic influences on RP processing. In addition, a longitudinal twin study reported considerable genetic influences (up to $56 \%$ heritability) on structural plasticity in the frontal and temporal cortices (Brans et al., 2010). Although music training-induced structural neuroplasticity has been welldocumented (see in this Research topic Barrett et al., 2013 and Merrett et al., 2013), this finding suggests that structural plasticity effects may also be genetically influenced.

In a large twin study conducted in 2001, $136 \mathrm{MZ}$ twin pairs and 148 DZ twin pairs undertook the Distorted Tunes Test (DTT), in which they judged whether simple well-known melodies contained incorrect pitches that rendered them "out-oftune" (Drayna et al., 2001). Twin structural modeling revealed a very high heritability estimate of $71-80 \%$ with no effect of shared environment, thus indicating a substantial genetic component influencing melodic perception ability.

A study conducted on 15 musical Finnish families investigated the genetic basis of music aptitude using three widely-used music perception tests: the Karma Music Test, and Seashore's pitch and rhythm discrimination tests (Pulli et al., 2008). The Seashore tasks use paired discrimination to assess pitch and rhythm perception (Radocy and Boyle, 2012), while the Karma Music Test assesses the ability to recognize patterns in sound sequences (Karma, 2007). Heritability estimates of 42, 57, 21, and 48\% were obtained for the Karma Music Test, Seashore's pitch and rhythm discrimination tests, and the combined score on all three tests, respectively. Genome-wide linkage analysis revealed significant evidence of linkage on chromosome 4 q22 (LOD $=3.33$ near markers D4S423 and D4S2460) and suggestive linkage evidence on chromosome region $8 \mathrm{q} 13-21(\mathrm{LOD}=2.29)$ for the combined score. Interestingly, the suggestive linkage peak at 8q13-21 was close to the linkage on chromosome $8 \mathrm{q} 21.11$ identified in the AP study by Theusch et al. (2009), pointing to a possible convergence of AP and general music perception abilities. A possible candidate gene at the tallest linkage peak of chromosome $4 \mathrm{q} 22$ is the netrin receptor $U N C 5 C$. Netrins are proteins that direct axon extension and cell migration during neural development, with studies showing interactions between netrins and robo family receptors (Stein and Tessier-Lavigne, 2001). One such receptor, $R O B O 1$, is a candidate gene for dyslexia (Carrion-Castillo et al., 
2013). One of the genes found on $8 \mathrm{q} 13-21$ is TRPA1, which was proposed as a non-essential subunit of the hair-cell transduction channel in the vertebrate inner ear (Corey, 2006). The authors of this study posited that the low selection pressure of TRPA1 may make it susceptible to mutations and perhaps lead to variability in the sound perception ability of individuals. Taken together, these linkage results suggest a genetic contribution to music perception underpinned by several predisposing genes on $4 \mathrm{q}$ and $8 \mathrm{q}$ (Pulli et al., 2008).

A follow-up candidate gene study involving 19 musical Finnish families found that the AVPR1A (arginine vasopressin 1a) haplotype $\mathrm{RS} 1+\mathrm{RS} 3$ on chromosome $12 \mathrm{q}$ has significant associations with performance on the Karma Music Test and the combined score on the Karma and Seashore music tasks (Ukkola et al., 2009). Analyses on the polymorphisms of other candidate genes such as SLC6A4, TPH1, and DRD2 yielded weak and inconclusive results. Previous studies have shown that arginine vasopressin (AVP) plays a key role in social cognition and behavior (Ferguson et al., 2002; Bielsky et al., 2004; Depue and Morrone-Strupinsky, 2005; Hammock and Young, 2005) and in social and spatial memory (Aarde and Jentsch, 2006). Its association with auditory pattern perception in this study suggests a potential link between music perception and human social functioning.

Using the same music perception measures as the two aforementioned studies, a recent study analyzed genome-wide CNVs in five multigenerational Finnish families and in 172 unrelated individuals (Ukkola-Vuoti et al., 2013). The CNV analysis detected several copy number variable regions (CNVRs) containing genes that influence neurodevelopment, learning and memory. Notably, a deletion on 5q31.1 was present in some participants who obtained a low combined score on the Karma and Seashore music tasks, accounting for 54\% of the low-scoring individuals from two families and 7\% of low-scoring unrelated participants. This particular CNVR covers the protocadherin- $\alpha$ gene cluster (Pcdha 1-9), which is implicated in neural migration, differentiation, and synaptogenesis, as well as learning and memory (Fukuda et al., 2008). Since learning and memory are crucial to music skill acquisition, including music perception (McLachlan et al., 2013a), the authors proposed that Pcdha may be a potential candidate gene influencing music perception and practice. Also noteworthy was the identification of a novel large 1.3Mb duplication on 8q24.22 in an individual with a low combined score. This region was previously reported as a major linkage region for AP (Theusch et al., 2009). As large duplications may have detrimental effects on neurodevelopment (Almal and Padh, 2012; Grayton et al., 2012), the authors speculated that a duplication in this region may have negatively impacted the participant's pitch perception accuracy. Due to the relatively small sample size and a lack of screening for neurocognitive deficits, the authors acknowledge that these results are preliminary, and there remains a possibility that the identified CNVs may not be predisposing for music perception per se.

In the first study to demonstrate a link between music perception and genes that are expressed in the auditory pathway, the same Finnish research group conducted a large-scale genomewide linkage and association study on the music perception abilities of 767 people from 76 Finnish families (Oikkonen et al.,
2014). Participants were again assessed using the Karma Music Test and the Seashore pitch and rhythm discrimination tasks, with estimated heritabilities for each test and the combined test score reported as $46,68,21$, and $60 \%$, respectively. While the heritability estimates for the Karma Music Test and the rhythm discrimination task are similar to the estimates reported by Pulli et al. (2008), the estimate for pitch discrimination is higher, which in turn may have inflated the heritability estimate for the combined test score. SNP linkage and association analyses uncovered multiple chromosomal regions containing auditory pathway genes. Specifically, the strongest association was observed on 3q21.3 (at SNP rs9854612) for the combined test score. Located close to $3 \mathrm{q} 21.3$ is the GATA2 (GATA binding protein 2) gene, which has been implicated in the development of the inner ear (Haugas et al., 2010) and the inferior colliculus (Lahti et al., 2013). The inferior colliculus is a key structure in the peripheral auditory pathways that supports the initial integration of pitch, direction and loudness information necessary for music perception (McLachlan and Wilson, 2010). Linkage analysis also revealed several linkage regions on chromosome 4, spanning 4p15 to $4 \mathrm{q} 24$. The strongest linkage was observed for the pitch discrimination task on chromosome $4 \mathrm{p} 14$, which is located next to the PCDH7 (protocadherin 7) gene. Notably, two SNPs (rs13146789 and rs13109270) of $P C D H 7$ also showed strong associations with the combined test score. $P C D H 7$ is expressed in the developing cochlea of the chicken and the amygdala of the mouse (Hertel et al., 2012; Lin et al., 2012), providing possible support for its role in music perception. Finally, some evidence of linkage was found on 4q21.23-22.1 and 4q24 for performance of the Karma Music Test, replicating the significant linkage on 4q22 reported by Pulli et al. (2008) for the combined test score. The current study, however, did not replicate the previously reported association between AVPR1A and music perception (Ukkola et al., 2009), nor did it observe any linkage or association evidence on 8q24.21, the putative AP region (Theusch et al., 2009).

In the rhythm domain, one study has reported that mutation of the FOXP2 (Forkhead box protein P2) gene on chromosome $7 q 31$ impairs rhythm perception and production, while leaving pitch perception and production abilities intact (Alcock et al., 2000). As FOXP2 has been implicated in an inherited speech and language disorder (Lai et al., 2001), these findings suggest a possible shared genetic basis for speech and rhythm, while pitchbased music abilities are likely influenced by other genetic factors (Peretz, 2009).

\section{Music memory}

There is evidence that six to eight-month old infants have already developed long-term memories for music and are able to distinguish between familiar and novel music (Saffran et al., 2000; Plantinga and Trainor, 2003). In addition, exposure to melodies presented prenatally for three weeks elicits significant heart rate change in one-month old infants compared to unexposed controls, suggesting that newborn infants are capable of retaining music representations up to six weeks following prenatal exposure (Granier-Deferre et al., 2011). Genetic determinants of memory have been reported in the broader literature, with some studies indicating that memory ability can be predicted by a 
particular SNP Val66Met variant of the BDNF (brain-derived neurotrophic factor) gene (Egan et al., 2003; Hariri et al., 2003). BDNF is evident in the hippocampus (a structure fundamental to new learning and memory) and has been implicated in neuronal growth, survival and maturation, including arborization and synaptic plasticity in the adult brain (Park and Poo, 2012).

In the only genetic study of music memory to date, Granot et al. (2007) investigated the possible association of phonological and music memory with the genes AVPR1A and SLC6A4 (solute carrier family 6 [neurotransmitter transporter serotonin], member 4). The rationale for targeting these two genes included a previously reported relationship between arginine vasopressin (AVP) and spatial and social memory (Ferguson et al., 2002; Aarde and Jentsch, 2006). There is also evidence that serotonin interacts with AVP in the hypothalamus (Albers et al., 2002) and that serotonin increases the secretion of AVP (Gálfi et al., 2005). This points to a possible epistatic relationship between the gene AVPR1A, which contains the blueprint to synthesize the AVP receptor, and the gene SLC6A4, which is the serotonin transporter protein crucial for regulating serotonin supply to serotonin receptors. In view of this, Granot et al. genotyped 82 university students with minimal music training for the AVPR1A (RS1 and RS3 haplotypes) and the SLC6A4 (HTTLPR) polymorphisms using populationbased and family-based association analyses. The phonological and music memory performance of the participants were assessed using an extensive battery of tests. Results revealed significant gene by gene epistatic interactions between the AVPR1A and SLC6A4 polymorphisms for two melodic memory tasks, one rhythmic memory task, and one phonological memory task, even after applying conservative Bonferroni corrections for multiple testing. This provides initial evidence for an epistatic relationship between AVPR1A and SLC6A4 polymorphisms that may be linked to short-term memory for music, or more generally, to phonological memory.

\section{Music Listening}

In another association study involving AVPR1A and SLC6A4 polymorphisms, Ukkola-Vuoti et al. (2011) investigated the music listening habits of 31 Finnish families using surveys. Familybased association analysis revealed positive associations between AVPR1A haplotypes and active music listening. The most significant associations occurred between the RS1+AVR haplotype and current active music listening, as well as the RS1+RS3 haplotype and lifelong active music listening. No significant association was observed between music listening and the SLC6A4 polymorphisms. In this study, active listening referred to attentive music listening, such as going to concerts. Since the same AVPR1A promoter region (RS1+RS3) was shown by Ukkola et al. (2009) to be associated with music perception, these findings suggest a common genetic background for the frequency of active music listening and music perception ability. Moreover, the authors reported that when music perception test scores and music education were covaried with music listening in the association analysis, the significant effect remained, indicating that music listening is independently associated with AVPR1A. More broadly, this association suggests that music listening may share common neurobiological pathways with social attachment and communication, given the well-established findings of AVP's mediating role in social behavior (Ferguson et al., 2002; Bielsky et al., 2004; Depue and Morrone-Strupinsky, 2005; Hammock and Young, 2005).

\section{MUSIC PRODUCTION ABILITIES \\ Singing}

Across all cultures humans have a propensity to sing. From two months onwards, infants begin to produce "musical babbling" containing definite music features such as pitch and rhythmic patterns (Welch, 2006). Most children begin imitating songs at approximately age two, by age four they can sing complete songs, and by age 5 most of them can accurately reproduce entire songs (McPherson and Williamon, 2006; Parncutt, 2006).

Although it is likely that variability in children's singing competency is, in part, attributable to environmental factors, such as early music exposure and training, a behavioral study has suggested there may also be an inborn aspect to singing accuracy. Watts et al. (2003) identified individuals who received no professional vocal training yet were described by professional voice teachers as "exhibiting expressed singing talent." These individuals showed consistently superior performance on pitch-matching tasks, especially in the absence of external auditory feedback, even when compared with trained singers who had at least three years of professional vocal training.

Park et al. (2012) investigated the genetic factors underpinning singing ability by conducting family-based linkage and association analyses on 1008 participants from 73 extended Mongolian families. They administered a pitch production accuracy test and found that 357 of the participants (35.4\%) were accurate pitchmatchers, reliably singing the target pitches with deviations less than a semitone. Using pedigree data, the heritability of singing accuracy was reported as $40 \%$. A genome-wide linkage analysis was then conducted, with the most significant linkage peak observed on 4q23 (LOD = 3.1 at marker D4S2986). The findings overlap with regions on chromosome 4q, where there is linkage evidence for music perception ability (Pulli et al., 2008; Oikkonen et al., 2014). A family-based association analysis performed at the putative linkage region revealed that SNP rs12510781 on 4 q26 was most significantly associated with singing accuracy. This is an intergenic SNP near the gene UGT8 (UDP glycosyltransferase 8), whose encoded protein is highly expressed in the brain, especially the substantia nigra (see online Supplementary Figure S2 of Park et al., 2012). The authors also utilized exome sequencing to find other potential candidate SNPs and discovered a non-synonymous SNP (rs4148254) in UGT8 on 4q26 that was significantly associated with singing accuracy. In addition, $\mathrm{CNV}$ analysis using an array comparative genomic hybridization (aCGH) platform showed that a copy number loss at $5.6 \mathrm{~kb}(5600$ base pairs) upstream of UGT8 may be negatively associated with singing accuracy. Although environmental factors such as education and music training were not considered in this study, the authors argued that because the participants resided in an isolated region with homogeneous culture and most were educated in the same school without additional music training, environmental factors were unlikely to impact greatly on the results. In other 
words, this study yields evidence that singing accuracy may be heritable in this population and possibly associated with a region on chromosome 4q.

\section{Participation in singing activities}

Coon and Carey (1989) analyzed the music ability of 11th grade twins by extracting music-related questionnaire data from an earlier study (Loehlin and Nichols, 1976). For participation in singing activities, the heritability estimates were reported as $71 \%$ for males and $20 \%$ for females, while the corresponding shared environment estimates were 8 and 59\% respectively. The significant gender difference in the estimates indicates that a shared environment exerted a stronger effect on females than males, while heritability was much higher in males than females. The authors suggested this may be due to a stereotypical perception that singing is a feminine activity and therefore, males might require greater interest and intrinsic ability to take part in such activities. As this study relied on self-reported data and did not objectively assess the singing ability of the twin pairs, more investigation is warranted to ascertain the genetic contribution to singing ability.

Similar to the association study on music memory by Granot et al. (2007), a candidate gene association study by Morley et al. (2012) tested the relationship between choir membership and allelic variants of the genes AVPR1A and SLC6A4. An overall association with choral singer status was observed at the STin2 (intron 2) polymorphism in the SLC6A4 gene, with the STin2 9-repeat and 12-repeat alleles being more common in choral singers, and the 10-repeat alleles more common in non-musically active controls. No significant differences in allele frequencies were observed between the two groups for other SLC6A4 and AVPR1A polymorphisms. Previous studies have reported possible involvement of STin2 in personality traits and reward behavior (Kazantseva et al., 2008; Zhong et al., 2009; Saiz et al., 2010). SLC6A4 polymorphisms (together with AVPR1A) have also been linked to participation in creative dance (Bachner-Melman et al., 2005). As several studies have observed associations between AVPR1A polymorphisms and certain music traits (Granot et al., 2007; Ukkola et al., 2009; Ukkola-Vuoti et al., 2011), the non-significant AVPR1A association in this study led the authors to speculate that the observed STin2 effect may predispose social behavioral characteristics (i.e., a "predisposed to group activity" phenotype) rather than music ability per se.

\section{Music creativity}

The genetic basis of music creativity was investigated in 19 Finnish musical families using a web-based questionnaire. Participants were asked about their music background and participation in creative music activities, such as music composition, improvisation or arrangement (Ukkola et al., 2009). The findings indicated that creative functions in music may have a strong genetic component in this sample population, with a heritability estimate of $84 \%$. A significant positive association between music creativity and high music perception test scores was also observed. However, no significant associations between music creativity and the polymorphisms of candidate genes such as TPH1, COMT, and AVPR1A were found.
Ukkola-Vuoti et al. (2013) performed a subsequent CNV analysis on five multigenerational Finnish families and 172 unrelated individuals using the same music creativity questionnaire. A "creative phenotype" was characterized by engagement in one or more creative music activities (composing, improvising or music arranging). Results showed that a deletion on $5 \mathrm{p} 15.33$ was present in $48 \%$ of family members and $28 \%$ of unrelated participants who exhibited the creative phenotype, while a duplication on 2 p22.1 was present in $27 \%$ of creative family members. The region $2 \mathrm{p} 22.1$ contains the gene GALM, which is associated with serotonin transporter binding potential in the human thalamus (Liu et al., 2011). The medial geniculate nucleus of the thalamus forms part of the auditory pathways, and more generally has been implicated in music-related functions such as beat perception (McAuley et al., 2012), sensorimotor synchronization (Krause et al., 2010) and musical imagery (Goycoolea et al., 2007). Other studies have found a link between the serotonin transporter gene (SLC6A4) and music-related functions such as choir participation (Morley et al., 2012) and creative dance (Bachner-Melman et al., 2005). On the other hand, deletions in three CNV regions (2p12, 3p14.1, and 3 q28) occurred quite commonly in individuals from two or more families without the creative phenotype, with frequencies ranging from 19 to $31 \%$. The authors acknowledged the preliminary nature of their findings, highlighting their use of uncorrected multiple comparisons. Replication of the findings is clearly warranted, including the use of objective measures of music creativity in future research.

\section{Self-reported music ability}

In addition to examining participation in singing activities in 11th grade twins, Coon and Carey (1989) used the music-related questionnaire data from Loehlin and Nichols (1976) to investigate other aspects of self-reported music ability, including interest in a music career, participation in music activities, out-of-school music performance experience, and receiving music prizes. Their results showed that while there were genetic influences, the effects of a shared environment were almost always larger across all the variables, with the exception of singing participation (described above) and out-of-school music performances in male twins. For participation in out-of-school music performances, the heritability estimates were reported as 38\% for males and $10 \%$ for females, while the corresponding shared environment estimates were 18 and $63 \%$ respectively. The researchers concluded that music ability is generally more influenced by shared environment than by shared genes in this young adult sample.

Interestingly, contrasting results were obtained in a more recent Netherlands twin study involving 1685 twin pairs aged 1224 years. Using a self-report questionnaire, this study examined the heritability of domain-specific aptitude (defined as ability within the normal range) and exceptional talent. In particular, the participants were asked to rate their level of competence in various domains such as music, arts, language and sports (Vinkhuyzen et al., 2009). For self-reported music aptitude, the heritability estimates for males and females were $66 \%$ and $30 \%$ and the shared environment estimates were 8 and 54\%, respectively. As for self-reported exceptional music talent, the heritability estimate was $92 \%$ with no shared environment effect. The 
authors concluded that genetic influences possibly account for the variation in aptitude and exceptional talent across domains, including intellect, creativity, and sporting ability to a large extent.

Similar to the music creativity research, both of the above twin studies lacked objective measures of music ability, raising concerns about the reliability of the findings.

\section{DISCUSSION}

As reviewed in this paper, a number of studies have begun to yield insights into the genetic basis of music ability. To date, some promising and converging findings have begun to emerge. Several loci on chromosome $8 \mathrm{q}$ have been implicated in more than one music trait. For instance, loci 8 q21 and 8 q24 have been implicated in AP ability and music perception (Pulli et al., 2008; Theusch et al., 2009; Ukkola-Vuoti et al., 2013). Similarly, loci 4 p14 and 4q22 on chromosome 4 have been implicated in music perception, particularly pitch discrimination (Pulli et al., 2008; Oikkonen et al., 2014), while the neighboring locus 4q23 has been implicated in pitch accuracy of singing (Park et al., 2012).

A number of genes have featured quite prominently in music genetics research to date. The gene AVPR1A on chromosome $12 \mathrm{q}$ has been implicated in music listening (Ukkola-Vuoti et al., 2011), music perception (Ukkola et al., 2009), and music memory (Granot et al., 2007). On the other hand, the gene SLC6A4 has been associated with music memory (Granot et al., 2007) and choir participation (Morley et al., 2012). The role of AVPR1A in social cognition and behavior has been well-investigated, as has the possible interaction between AVPR1A and SLC6A4 in communicative behavior. The associations of these two genes with various music functions raises the intriguing possibility of an overlap in the neurobiological basis of music functions and social behavior.

Replication of the results of existing studies is necessary to confirm the findings, especially in those studies with small sample sizes (e.g., Granot et al., 2007; Pulli et al., 2008; Ukkola-Vuoti et al., 2013). For instance, a recent large genome-wide linkage and association study (Oikkonen et al., 2014) failed to observe an association between $A V P R 1 A$ and music perception, which had previously been reported in a candidate gene study by the same research group (Ukkola et al., 2009). In many of the candidate gene association studies, the polymorphisms of genes such as $A V P R 1 A$ and SLC6A4 were chosen as candidates based on suggestive results from other music studies. However, the multi-faceted nature of music ability may render a candidate gene associated with one musical function a weak candidate for another musical function. This is illustrated by the study of Morley et al. (2012), which found no association between AVPR1A polymorphisms and choir participation despite having adequate statistical power. It may thus be more prudent for researchers to select candidate genes based on supporting evidence from linkage analysis or GWAS of related music abilities. It is also important to note that candidate gene studies have a poor record of replication, with negative findings likely under-reported due to publication bias for positive findings (Ott, 2004; Lewis and Knight, 2012).

In replicating the findings of current studies, it will be important for future studies to use alternate populations and larger samples. It is apparent from Tables 2, 3 that a significant number of molecular genetic studies have been conducted on several multigenerational Finnish families. Extending the findings from these families to other ethnic populations would serve to validate the reported associations. More generally, conducting GWAS in populations of different ancestries has been identified as a key area for future medical genetics research, as the different linkage disequilibrium (LD) structure of different populations may help to refine a gene locus of interest (Stranger et al., 2011), and in some cases it may increase the statistical power to detect an association (Pulit et al., 2010). Increased research efforts toward replication will also add to the number of independent molecular genetic studies available for meta-analysis, which in turn, will increase the sample size and statistical power of meta-analyses to detect associations with modest effects (Stranger et al., 2011; Rowe and Tenesa, 2012).

As molecular genetics research in music is still in its infancy, many of the molecular studies reviewed in this paper utilized earlier molecular genetic methods such as linkage mapping or the candidate gene approach. Technological advances now make it possible for commercial arrays to include a combination of SNPs and structural genetic variants (such as CNVs) (McCarroll, 2008). Music genetics researchers can consider integrating these approaches, with findings yielded from $\mathrm{CNV}$ analysis able to complement those from SNP analysis (Stranger et al., 2007). Other recent methods include exome sequencing, which provides a more cost-effective and efficient alternative to whole genome sequencing, as well as methylation studies, which can be used to investigate the potential contribution of epigenetic influences and the underlying molecular and biological mechanisms of a trait (Rowe and Tenesa, 2012). Future studies of the genetic basis of music would therefore likely benefit from a shift toward more current molecular genetic methods to investigate complex traits, especially while new approaches for integrating and analyzing diverse data types are being developed (Battle et al., 2010).

Another important, but as yet under-researched avenue of music genetics research involves exploration of the potential contributions of epistasis, gene-environment interactions, and epigenetic influences on music ability. These factors may explain why many of the genetic variants and loci implicated in complex traits could only account for a small percentage of the heritability estimated from family studies (Stranger et al., 2011). Music researchers need to move away from the dichotomous view of nature vs. nurture and develop an awareness of the intricate interplay between genes and environment. For instance, there may be possible genetic influences on ostensibly environmental components such as training-induced neural plasticity (Brans et al., 2010; Vinkhuyzen et al., 2010). Conversely, environmental factors may alter gene expression through epigenetic mechanisms (Fagiolini et al., 2009; Sweatt, 2013).

While the results garnered to date are promising, a more comprehensive investigation of music ability is warranted, including more precise characterization of music phenotypes to identify their genetic basis. As evident from Table 1, the majority of studies have used tests of music aptitude to operationalize music ability, producing an undue emphasis on certain perceptual skills, such as pitch and rhythm discrimination, while ignoring others. This means that other equally important perceptual 
skills, as well as music production abilities, creativity, sensitivity and expressivity have received minimal investigation. The multifaceted nature of music ability calls for identification and then careful delineation of the range of music phenotypes, with greater research efforts directed toward phenotypes that have been scantly researched. Conceivably, proper characterization of music phenotypes will facilitate identification of relevant genes predisposing these phenotypes through rigorous genetic studies (Levitin, 2012). Music deficits, such as tone deafness (Peretz et al., 2007) and beat deafness (Phillips-Silver et al., 2011), also offer fruitful avenues for further investigation as deficits often have more distinct phenotypic outcomes than abilities. Currently, few genetic studies have focused on music deficits. In addition, a dearth of research effort has been directed toward investigating a possible overlap in the genetic bases of language and music abilities. Our current knowledge is limited to the finding that FOXP2 may play a role in music rhythm processing as well as language and speech (Alcock et al., 2000; Lai et al., 2001). Comparative genetic research between music and language abilities promises to advance our understanding of the shared and non-shared genetic and neurobiological mechanisms underpinning music and language, and may help elucidate important questions about the origins of music and language (Peretz, 2009).

In conclusion, although currently there is only a handful of research studies in this area, music genetics research has yielded promising preliminary results, highlighting the need for increased research effort in this emerging field. Elucidating the genetic basis of music ability may be challenging due to its multifaceted nature, necessitating careful identification, characterization, and genetic investigation of its many different facets. Coupled with the propitious rate at which molecular genetics and statistical designs are advancing, an increasingly clearer picture of the genetic mechanisms underpinning the etiology of music traits will begin to emerge. These mechanisms may then be linked to established neuroscientific findings of the neurobiological basis of specific music functions and behaviors. Ultimately, this will allow us to gain a deeper understanding of the way in which interactions between nature and nurture shape the development of human music ability over the lifespan.

\section{ACKNOWLEDGMENT}

The authors would like to thank the reviewers for their valuable suggestions and comments on this review article.

\section{SUPPLEMENTARY MATERIAL}

The Supplementary Material for this article can be found online at: http://www.frontiersin.org/journal/10.3389/fpsyg.2014. 00658/abstract

\section{REFERENCES}

Aarde, S. M., and Jentsch, J. D. (2006). Haploinsufficiency of the argininevasopressin gene is associated with poor spatial working memory performance in rats. Horm. Behav. 49, 501-508. doi: 10.1016/j.yhbeh.2005.11.002

Albers, H. E., Karom, M., and Smith, D. (2002). Serotonin and vasopressin interact in the hypothalamus to control communicative behavior. Neuroreport 13, 931-933. doi: 10.1097/00001756-200205240-00006

Alcock, K. J., Passingham, R. E., Watkins, K., and Vargha-Khadem, F. (2000). Pitch and timing abilities in inherited speech and language impairment. Brain Lang. 75, 34-46. doi: 10.1006/brln.2000.2323
Alkan, C., Coe, B. P., and Eichler, E. E. (2011). Genome structural variation discovery and genotyping. Nat. Rev. Genet. 12, 363-376. doi: 10.1038/nrg2958

Almal, S. H., and Padh, H. (2012). Implications of gene copy-number variation in health and diseases. J. Hum. Genet. 57, 6-13. doi: 10.1038/jhg.2011.108

Attia, J., Ioannidis, J. P. A., Thakkinstian, A., McEvoy, M., Scott, R. J., Minelli, C., et al. (2009). How to use an article about genetic association B: are the results of the study valid? J. Am. Med. Assoc. 301, 191-197. doi: 10.1001/jama.2008.946

Bachem, A. (1955). Absolute pitch. J. Acoust. Soc. Am. 11, 434-439. doi: $10.1121 / 1.1916056$

Bachner-Melman, R., Dina, C., Zohar, A. H., Constantini, N., Lerer, E., Hoch, S., et al. (2005). AVPRla and SLC6A4 gene polymorphisms are associated with creative dance performance. PLoS Genet. 1:e42. doi: 10.1371/journal.pgen.0010042

Baharloo, S., Johnston, P. A., Service, S. K., Gitschier, J., and Freimer, N. B. (1998). Absolute pitch: an approach for identification of genetic and nongenetic components. Am. J. Hum. Genet. 62, 224-231. doi: 10.1086/301704

Baharloo, S., Service, S. K., Risch, N., Gitschier, J., and Freimer, N. B. (2000). Familial aggregation of absolute pitch. Am. J. Hum. Genet. 67, 755-758. doi: $10.1086 / 303057$

Barrett, K. C., Ashley, R., Strait, D. L., and Kraus, N. (2013). Art and science: how musical training shapes the brain. Front. Psychol. 4:713. doi: 10.3389/fpsyg.2013.00713

Battle, A., Jonikas, M. C., Walter, P., Weissman, J. S., and Koller, D. (2010). Automated identification of pathways from quantitative genetic interaction data. Mol. Syst. Biol. 6:379. doi: 10.1038/msb.2010.27

Bielsky, I. F., Hu, S. B., Szegda, K. L., Westphal, H., and Young, L. J. (2004). Profound impairment in social recognition and reduction in anxiety-like behavior in vasopressin V1a receptor knockout mice. Neuropsychopharmacology 29, 483-493. doi: 10.1038/sj.npp.1300360

Bochud, M. (2012). "Estimating heritability from nuclear family and pedigree data," in Statistical Human Genetics: Methods and Protocols, eds R. C. Elston, J. M. Satagopan, and S. Sun (New York, NY: Humana Press; Springer), 171-186.

Borkenau, P., Riemann, R., Angleitner, A., and Spinath, F. M. (2002). Similarity of childhood experiences and personality resemblance in monozygotic and dizygotic twins: a test of the equal environments assumption. Pers. Individ. Dif. 33, 261-269. doi: 10.1016/S0191-8869(01)00150-7

Brans, R. G. H., Kahn, R., Schnack, H. G., Van Baal, G. C. M., Posthuma, D., Van Haren, N. E. M., et al. (2010). Brain plasticity and intellectual ability are influenced by shared genes. J. Neurosci. 30, 5519-5524. doi: 10.1523/JNEUROSCI.5841-09.2010

Carey, G. (ed.). (2003a). “Chapter 10: Morgan and linkage”, in Human Genetics for the Social Sciences (Thousand Oaks, CA: Sage Publications, Inc.), 161-180.

Carey, G. (ed.). (2003b). "Chapter 11: the association study," in Human Genetics for the Social Sciences (Thousand Oaks, CA: Sage Publications, Inc.), 181-192.

Carrion-Castillo, A., Franke, B., and Fisher, S. E. (2013). Molecular genetics of dyslexia: an overview. Dyslexia 19, 214-240. doi: 10.1002/dys.1464

Coon, H., and Carey, G. (1989). Genetic and environmental determinants of musical ability in twins. Behav. Genet. 19, 183-193. doi: 10.1007/BF01065903

Corey, D. P. (2006). What is the hair cell transduction channel? J. Physiol. 576, 23-28. doi: 10.1113/jphysiol.2006.116582

Coughlin, C. R., Scharer, G. H., and Shaikh, T. H. (2012). Clinical impact of copy number variation analysis using high-resolution microarray technologies: advantages, limitations and concerns. Genome Med. 4:80. doi: 10.1186/gm381

Depue, R. A., and Morrone-Strupinsky, J. V. (2005). A neurobehavioral model of affiliative bonding: implications for conceptualizing a human trait of affiliation. Behav. Brain Sci. 28, 313-350. doi: 10.1017/S0140525X05000063

De Quervain, D. J. F., and Papassotiropoulos, A. (2006). Identification of a genetic cluster influencing memory performance and hippocampal activity in humans. Proc. Natl. Acad. Sci. U.S.A. 103, 4270-4274. doi: 10.1073/pnas.0510212103

Dovern, A., Fink, G. R., Fromme, A. C. B., Wohlschläger, A. M., Weiss, P. H., and Riedl, V. (2012). Intrinsic network connectivity reflects consistency of synesthetic experiences. J. Neurosci. 32, 7614-7621. doi: 10.1523/JNEUROSCI.540111.2012

Drayna, D., Manichaikul, A., De Lange, M., Snieder, H., and Spector, T. (2001). Genetic correlates of musical pitch recognition in humans. Science 291, 1969-1972. doi: 10.1126/science.291.5510.1969

Egan, M. F., Kojima, M., Callicott, J. H., Goldberg, T. E., Kolachana, B. S., Bertolino, A., et al. (2003). The BDNF val66met polymorphism affects activity-dependent secretion of BDNF and human memory and hippocampal function. Cell 112, 257-269. doi: 10.1016/S0092-8674(03)00035-7 
Fagiolini, M., Jensen, C. L., and Champagne, F. A. (2009). Epigenetic influences on brain development and plasticity. Curr. Opin. Neurobiol. 19, 207-212. doi: 10.1016/j.conb.2009.05.009

Ferguson, J. N., Young, L. J., and Insel, T. R. (2002). The neuroendocrine basis of social recognition. Front. Neuroendocrinol. 23, 200-224. doi: 10.1006/frne.2002.0229

Foster, N. E. V., and Zatorre, R. J. (2010). Cortical structure predicts success in performing musical transformation judgments. Neuroimage 53, 26-36. doi: 10.1016/j.neuroimage.2010.06.042

Fukuda, E., Hamada, S., Hasegawa, S., Katori, S., Sanbo, M., Miyakawa, T., et al. (2008). Down-regulation of protocadherin- $\alpha$ A isoforms in mice changes contextual fear conditioning and spatial working memory. Eur. J. Neurosci. 28, 1362-1376. doi: 10.1111/j.1460-9568.2008.06428.x

Gaab, N., Gaser, C., and Schlaug, G. (2006). Improvement-related functional plasticity following pitch memory training. Neuroimage 31, 255-263. doi: 10.1016/j.neuroimage.2005.11.046

Gálfi, M., Radács, M., Juhász, A., László, F., Molnár, A., and László, F. A. (2005). Serotonin-induced enhancement of vasopressin and oxytocin secretion in rat neurohypophyseal tissue culture. Regul. Pept. 127, 225-231. doi: 10.1016/j.regpep.2004.12.009

Goycoolea, M. V., Mena, I., Neubauer, S. G., Levy, R. G., Grez, M. F., and Berger, C. G. (2007). Musical brains: a study of spontaneous and evoked musical sensations without external auditory stimuli. Acta Otolaryngol. 127, 711-721. doi: 10.1080/00016480601053057

Graham, S. A., and Fisher, S. E. (2013). Decoding the genetics of speech and language. Curr. Opin. Neurobiol. 23, 43-51. doi: 10.1016/j.conb.2012.11.006

Granier-Deferre, C., Bassereau, S., Ribeiro, A., Jacquet, A. Y., and DeCasper, A. J. (2011). A melodic contour repeatedly experienced by human near-term fetuses elicits a profound cardiac reaction one month after birth. PLOS ONE 6:2. doi: 10.1371/journal.pone.0017304

Granot, R. Y., Frankel, Y., Gritsenko, V., Lerer, E., Gritsenko, I., Bachner-Melman, R., et al. (2007). Provisional evidence that the arginine vasopressin la receptor gene is associated with musical memory. Evolut. Hum. Behav. 28, 313-318. doi: 10.1016/j.evolhumbehav.2007.05.003

Grayton, H. M., Fernandes, C., Rujescu, D., and Collier, D. A. (2012). Copy number variations in neurodevelopmental disorders. Prog. Neurobiol. 99, 81-91. doi: 10.1016/j.pneurobio.2012.07.005

Gregersen, P. K. (1998). Instant recognition: the genetics of pitch perception. Am. J. Hum. Genet. 62, 221-223. doi: 10.1086/301734

Gregersen, P. K., Kowalsky, E., Kohn, N., and Marvin, E. W. (1999). Absolute pitch: prevalence, ethnic variation, and estimation of the genetic component. Am. J. Hum. Genet. 65, 911-913. doi: 10.1086/302541

Gregersen, P. K., Kowalsky, E., Kohn, N., and Marvin, E. W. (2001). Early childhood music education and predisposition to absolute pitch: teasing apart genes and environment. Am. J. Med. Genet. 98, 280-282. doi: 10.1002/1096-8628(2001 0122)98:3<280::AID-AJMG1083>3.0.CO;2-6

Gregersen, P. K., Kowalsky, E., Lee, A., Baron-Cohen, S., Fisher, S. E., Asher, J. E., et al. (2013). Absolute pitch exhibits phenotypic and genetic overlap with synesthesia. Hum. Mol. Genet. 22, 2097-2104. doi: 10.1093/hmg/ddt059

Gregersen, P. K., Kowalsky, E., and Li, W. T. (2007). Reply to Henthorn and Deutsch: ethnicity versus early environment: comment on "Early childhood music education and predisposition to absolute pitch: Teasing apart genes and environment" by Peter K. Gregersen, Elena Kowalsky, Nina Kohn, and Elizabeth West Marvin [2000]. Am. J. Med. Genet. 143A, 104-105. doi: 10.1002/ajmg.a. 31595

Gregersen, P. K., and Kumar, S. (1996). The genetics of perfect pitch. Am. J. Hum. Genet. 59(Suppl.), A179.

Guo, S. W. (1998). Inflation of sibling recurrence-risk ratio, due to ascertainment bias and/or overreporting. Am. J. Hum. Genet. 63, 252-258. doi: 10.1086/301928

Hammock, E. A. D., and Young, L. J. (2005). Microsatellite instability generates diversity in brain and sociobehavioral traits. Science 308, 1630-1634. doi: $10.1126 /$ science. 1111427

Hariri, A. R., Goldberg, T. E., Mattay, V. S., Kolachana, B. S., Callicott, J. H., Egan, M. F., et al. (2003). Brain-derived neurotrophic factor val66met polymorphism affects human memory-related hippocampal activity and predicts memory performance. J. Neurosci. 23, 6690-6694.

Haugas, M., Lilleväli, K., Hakanen, J., and Salminen, M. (2010). Gata2 is required for the development of inner ear semicircular ducts and the surrounding perilymphatic space. Dev. Dyn. 239, 2452-2469. doi: 10.1002/dvdy.22373
He, C., and Trainor, L. J. (2009). Finding the pitch of the missing fundamental in infants. J. Neurosci. 29, 7718-7722. doi: 10.1523/JNEUROSCI.0157-09.2009

Henthorn, T., and Deutsch, D. (2007). Ethnicity versus early environment: comment on 'Early childhood music education and predisposition to absolute pitch: teasing apart genes and environment' by Peter K. Gregersen, Elena Kowalsky, Nina Kohn, and Elizabeth West Marvin [2000]. Am. J. Med. Genet. A 143, 102-103. doi: 10.1002/ajmg.a.31596

Hertel, N., Redies, C., and Medina, L. (2012). Cadherin expression delineates the divisions of the postnatal and adult mouse amygdala. J. Comp. Neurol. 520, 3982-4012. doi: 10.1002/cne.23140

Honing, H., Ladinig, O., Háden, G. P., and Winkler, I. (2009). Is beat induction innate or learned: probing emergent meter perception in adults and newborns using event-related brain potentials. Ann. N.Y. Acad. Sci. 1169, 93-96. doi: 10.1111/j.1749-6632.2009.04761.x

Hove, M. J., Sutherland, M. E., and Krumhansl, C. L. (2010). Ethnicity effects in relative pitch. Psychon. Bull. Rev. 17, 310-316. doi: 10.3758/PBR.17.3.310

Hyde, K. L., Lerch, J. P., Zatorre, R. J., Griffiths, T. D., Evans, A. C., and Peretz, I. (2007). Cortical thickness in congenital amusia: when less is better than more. J. Neurosci. 27, 13028-13032. doi: 10.1523/JNEUROSCI.303907.2007

Jäncke, L., Gaab, N., Wüstenberg, T., Scheich, H., and Heinze, H. J. (2001). Shortterm functional plasticity in the human auditory cortex: an fMRI study. Cogn. Brain Res. 12, 479-485. doi: 10.1016/S0926-6410(01)00092-1

Kalmus, H., and Fry, D. B. (1980). On tune deafness (dysmelodia): frequency, development, genetics and musical background. Ann. Hum. Genet. 43, 369-382. doi: 10.1111/j.1469-1809.1980.tb01571.x

Karma, K. (2007). Musical aptitude definition and measure validation: ecological validity can endanger the construct validity of musical aptitude tests. Psychomusicology 19, 79-90. doi: 10.1037/h0094033

Kazantseva, A. V., Gaysina, D. A., Faskhutdinova, G. G., Noskova, T., Malykh, S. B., and Khusnutdinova, E. K. (2008). Polymorphisms of the serotonin transporter gene (5-HTTLPR, A/G SNP in 5-HTTLPR, and STin2 VNTR) and their relation to personality traits in healthy individuals from Russia. Psychiatr. Genet. 18, 167-176. doi: 10.1097/YPG.0b013e328304deb8

Keenan, J. P., Thangaraj, V., Halpern, A. R., and Schlaug, G. (2001). Absolute pitch and planum temporale. Neuroimage 14, 1402-1408. doi: 10.1006/nimg.2001.0925

Krause, V., Schnitzler, A., and Pollok, B. (2010). Functional network interactions during sensorimotor synchronization in musicians and non-musicians. Neuroimage 52, 245-251. doi: 10.1016/j.neuroimage.2010.03.081

Ku, C. S., Cooper, D. N., Polychronakos, C., Naidoo, N., Wu, M., and Soong, R. (2012). Exome sequencing: dual role as a discovery and diagnostic tool. Ann. Neurol. 71, 5-14. doi: 10.1002/ana.22647

Kubozono, H. (2012). Varieties of pitch accent systems in Japanese. Lingua 122, 1395-1414. doi: 10.1016/j.lingua.2012.08.001

Lahti, L., Achim, K., and Partanen, J. (2013). Molecular regulation of GABAergic neuron differentiation and diversity in the developing midbrain. Acta Physiol. 207, 616-627. doi: 10.1111/apha.12062

Lai, C. S. L., Fisher, S. E., Hurst, J. A., Vargha-Khadem, F., and Monaco, A. P. (2001). A forkhead-domain gene is mutated in a severe speech and language disorder. Nature 413, 519-523. doi: 10.1038/35097076

Lathrop, G. M., Lalouel, J. M., Julier, C., and Ott, J. (1984). Strategies for multilocus linkage analysis in humans. Proc. Natl. Acad. Sci. U.S.A. 81, 3443-3446. doi: $10.1073 /$ pnas.81.11.3443

Levitin, D. J. (2012). What does it mean to be musical? Neuron 73, 633-637. doi: 10.1016/j.neuron.2012.01.017

Lewis, C. M., and Knight, J. (2012). Introduction to genetic association studies. Cold Spring Harb. Protoc. 7, 297-306. doi: 10.1101/pdb.top068163

Li, C. C., Chakravarti, A., and Halloran, S. L. (1987). Estimation of segregation and ascertainment probabilities by discarding the single probands. Genet. Epidemiol. 4, 185-191. doi: 10.1002/gepi.1370040303

Li, C. C., and Mantel, N. (1968). A simple method of estimating the segregation ratio under complete ascertainment. Am. J. Hum. Genet. 20, 61-81.

Lin, J., Yan, X., Wang, C., Guo, Z., Rolfs, A., and Luo, J. (2012). Anatomical expression patterns of delta-protocadherins in developing chicken cochlea. J. Anat. 221, 598-608. doi: 10.1111/j.1469-7580.2012.01568.x

Liu, X., Cannon, D. M., Akula, N., Moya, P. R., Knudsen, G. M., Arentzen, T. E., et al. (2011). A non-synonymous polymorphism in galactose mutarotase (GALM) is associated with serotonin transporter binding potential in the 
human thalamus: results of a genome-wide association study. Mol. Psychiatry 16, 584-594. doi: 10.1038/mp.2011.1

Loehlin, J. C., and Nichols, R. C. (1976). Heredity, Environment and Personality: A Study of 850 Sets of Twins. Austin, TX: University of Texas Press.

Loui, P., Alsop, D., and Schlaug, G. (2009). Tone deafness: a new disconnection syndrome? J. Neurosci. 29, 10215-10220. doi: 10.1523/JNEUROSCI.1701-09.2009

Loui, P., Li, H. C., Hohmann, A., and Schlaug, G. (2011). Enhanced cortical connectivity in absolute pitch musicians: a model for local hyperconnectivity. J. Cogn. Neurosci. 23, 1015-1026. doi: 10.1162/jocn.2010.21500

Ludwig, M. G., and Seuwen, K. (2002). Characterization of the human adenylyl cyclase gene family: cDNA, gene structure, and tissue distribution of the nine isoforms. J. Recept. Signal Transduct. 22, 79-110. doi: 10.1081/RRS-120014589

Mandell, J., Schulze, K., and Schlaug, G. (2007). Congenital amusia: an auditorymotor feedback disorder? Restor. Neurol. Neurosci. 25, 323-334.

McAuley, J. D., Henry, M. J., and Tkach, J. (2012). Tempo mediates the involvement of motor areas in beat perception. Ann. N.Y. Acad. Sci. 1252, 77-84. doi: 10.1111/j.1749-6632.2011.06433.x

McCarroll, S. A. (2008). Extending genome-wide association studies to copynumber variation. Hum. Mol. Genet. 17, R135-R142. doi: 10.1093/hmg/ddn282

McDermott, J., and Hauser, M. (2005). The origins of music: innateness, uniqueness, and evolution. Music Percept. 23, 29-59. doi: 10.1525/mp.2005.23.1.29

McLachlan, N., Marco, D., Light, M., and Wilson, S. (2013a). Consonance and pitch. J. Exp. Psychol. Gen. 142, 1142-1158. doi: 10.1037/a0030830

McLachlan, N., Marco, D., and Wilson, S. (2013b). Pitch and plasticity: insights from the pitch matching of chords by musicians with absolute and relative pitch. Brain Sci. 3, 1615-1634. doi: 10.3390/brainsci3041615

McLachlan, N., and Wilson, S. (2010). The central role of recognition in auditory perception: a neurobiological model. Psychol. Rev. 117, 175-196. doi: $10.1037 / \mathrm{a} 0018063$

McPherson, G. E., and Williamon, A. (2006). "Giftedness and talent", in The Child as Musician: A Handbook of Musical Development, ed G. E. McPherson (New York, NY: Oxford University Press), 239-256. doi: 10.1093/acprof:oso/ 9780198530329.003.0012

Merrett, D. L., Peretz, I., and Wilson, S. J. (2013). Moderating variables of music training-induced neuroplasticity: a review and discussion. Front. Psychol. 4:606. doi: 10.3389/fpsyg.2013.00606

Mignault Goulet, G., Moreau, P., Robitaille, N., and Peretz, I. (2012). Congenital amusia persists in the developing brain after daily music listening. PLoS ONE 7:e36860. doi: 10.1371/journal.pone.0036860

Mitry, D., Williams, L., Charteris, D. G., Fleck, B. W., Wright, A. F., and Campbell, H. (2011). Population-based estimate of the sibling recurrence risk ratio for rhegmatogenous retinal detachment. Invest. Ophthalmol. Vis. Sci. 52, 2551-2555. doi: 10.1167/iovs.10-6375

Miyazaki, K. (1988). Musical pitch identification by absolute pitch possessors. Percept. Psychophys. 44, 501-512. doi: 10.3758/BF03207484

Morley, A. P., Narayanan, M., Mines, R., Molokhia, A., Baxter, S., Craig, G., et al. (2012). AVPR1A and SLC6A4 polymorphisms in choral singers and nonmusicians: a gene association study. PLoS ONE 7:e31763. doi: 10.1371/journal.pone. 0031763

Naj, A. C., Park, Y. S., and Beaty, T. H. (2012). "Detecting familial aggregation,” in Statistical Human Genetics: Methods and Protocols, eds R. C. Elston, J. M. Satagopan, and S. Sun (New York, NY: Humana Press; Springer), 119-150.

Nandram, B., Jai-Won, C., and Hongyan, X. (2011). Maximum likelihood estimation for ascertainment bias in sampling siblings. J. Data Sci. 9, 23.

Neale, M. C., Boker, S. M., Xie, G., and Maes, H. H. (2006). Mx: Statistical Modeling. Richmond, VA: Department of Psychiatry.

Newbury, D. F., and Monaco, A. P. (2010). Genetic advances in the study of speech and language disorders. Neuron 68, 309-320. doi: 10.1016/j.neuron.2010.10.001

Ng, S. B., Turner, E. H., Robertson, P. D., Flygare, S. D., Bigham, A. W., Lee, C., et al. (2009). Targeted capture and massively parallel sequencing of 12 human exomes. Nature 461, 272-276. doi: 10.1038/nature08250

North, H. A., Clifford, M. A., and Donoghue, M. J. (2013). 'Til Eph do us part': intercellular signaling via Eph receptors and ephrin ligands guides cerebral cortical development from birth through maturation. Cereb. Cortex 23, 1765-1773. doi: $10.1093 /$ cercor/bhs 183

Nsengimana, J., and Bishop, D. T. (2012). "Design considerations for genetic linkage and association studies," in Statistical Human Genetics: Methods and Protocols, eds R. C. Elston, J. M. Satagopan, and S. Sun (New York, NY: Humana Press; Springer), 237-262.
Oikkonen, J., Huang, Y., Onkamo, P., Ukkola-Vuoti, L., Raijas, P., Karma, K., et al. (2014). A genome-wide linkage and association study of musical aptitude identifies loci containing genes related to inner ear development and neurocognitive functions. Mol. Psychiatry. doi: 10.1038/mp.2014.8. [Epub ahead of print].

Ott, J. (2004). Association of genetic loci: replication or not, that is the question. Neurology 63, 955-958. doi: 10.1212/WNL.63.6.955

Park, H., Lee, S., Kim, H. J., Ju, Y. S., Shin, J. Y., Hong, D., et al. (2012) Comprehensive genomic analyses associate UGT8 variants with musical ability in a Mongolian population. J. Med. Genet. 49, 747-752. doi: 10.1136/jmedgenet2012-101209

Park, H., and Poo, M. M. (2012). Neurotrophin regulation of neural circuit development and function. Nat. Rev. Neurosci. 14, 7-23. doi: 10.1038/nrn3379

Parncutt, R. (2006). "Prenatal development," in The Child as Musician: A Handbook of Musical Development, ed G. E. McPherson (Oxford: Oxford University Press), 1-32. doi: 10.1093/acprof:oso/9780198530329.003.0001

Peper, J. S., Brouwer, R. M., Boomsma, D. I., Kahn, R. S., and Hulshoff Pol, H. E. (2007). Genetic influences on human brain structure: a review of brain imaging studies in twins. Hum. Brain Mapp. 28, 464-473. doi: 10.1002/hbm. 20398

Peretz, I. (2009). Music, language and modularity framed in action. Psychol. Belg. 49, 157-175. doi: 10.5334/pb-49-2-3-157

Peretz, I., Cummings, S., and Dubé, M.-P. (2007). The genetics of congenital amusia (tone deafness): a family-aggregation study. Am. J. Hum. Genet. 81, 582-588. doi: $10.1086 / 521337$

Peretz, I., and Hyde, K. (2003). What is specific to music processing? Insights from congenital amusia. Trends Cogn. Sci. 7, 362-367. doi: 10.1016/S13646613(03)00150-5

Phillips-Silver, J., Toiviainen, P., Gosselin, N., Piché, O., Nozaradan, S., Palmer, C., et al. (2011). Born to dance but beat deaf: a new form of congenital amusia. Neuropsychologia 49, 961-969. doi: 10.1016/j.neuropsychologia.2011.02.002

Plantinga, J., and Trainor, L. J. (2003). Long-term memory for pitch in six-monthold infants. Ann. N.Y. Acad. Sci. 999, 520-521. doi: 10.1196/annals.1284.064

Plomin, R., Willerman, L., and Loehlin, J. C. (1976). Resemblance in appearance and the equal environments assumption in twin studies of personality traits. Behav. Genet. 6, 43-52. doi: 10.1007/BF01065677

Profita, J., and Bidder, T. G. (1988). Perfect pitch. Am. J. Med. Genet. 29, 763-771. doi: 10.1002/ajmg.1320290405

Pulit, S. L., Voight, B., and de Bakker, P. I. W. (2010). Multiethnic genetic association studies improve power for locus discovery. PLOS ONE 5:e12600. doi: 10.1371/journal.pone.0012600

Pulli, K., Karma, K., Norio, R., Sistonen, P., Göring, H. H. H., and Järvelä, I. (2008). Genome-wide linkage scan for loci of musical aptitude in Finnish families: evidence for a major locus at 4q22. J. Med. Genet. 45, 451-456. doi: 10.1136/jmg.2007.056366

Radocy, R. E., and Boyle, J. D. (2012). Psychological Foundations of Musical Behaviour. 5th Edn. Springfield, IL: Charles C. Thomas Publisher, Ltd.

Raskind, W. H., Peter, B., Richards, T., Eckert, M. M., and Berninger, V. W. (2013). The genetics of reading disabilities: from phenotypes to candidate genes. Front. Psychol. 3:601. doi: 10.3389/fpsyg.2012.00601

Reich, D. E., and Lander, E. S. (2001). On the allelic spectrum of human disease. Trends Genet. 17, 502-510. doi: 10.1016/S0168-9525(01)02410-6

Richardson, K., and Norgate, S. (2005). The equal environments assumption of classical twin studies may not hold. Br. J. Educ. Psychol. 75, 339-350. doi: 10.1348/000709904X24690

Ross, D. A., Olson, I. R., and Gore, J. C. (2003). Absolute pitch does not depend on early musical training. Ann. N.Y. Acad. Sci. 999, 522-526. doi: 10.1196/annals. 1284.065

Rouw, R., and Scholte, H. S. (2007). Increased structural connectivity in graphemecolor synesthesia. Nat. Neurosci. 10, 792-797. doi: 10.1038/nn1906

Rowe, S. J., and Tenesa, A. (2012). Human complex trait genetics: lifting the lid of the genomics toolbox - from pathways to prediction. Curr. Genomics 13, 213-224. doi: 10.2174/138920212800543101

Saffran, J. R., Loman, M. M., and Robertson, R. R. W. (2000). Infant memory for musical experiences. Cognition 77, B15-B23. doi: 10.1016/S00100277(00)00095-0

Saiz, P. A., Garcia-Portilla, M. P., Herrero, R., Arango, C., Corcoran, P., Morales, B., et al. (2010). Interactions between functional serotonergic polymorphisms and demographic factors influence personality traits in healthy Spanish Caucasians. Psychiatr. Genet. 20, 171-178. doi: 10.1097/YPG.0b013e32833a20b9 
Schnell, A. H., and Sun, X. (2012). "Model-based linkage analysis of a quantitative trait," in Statistical Human Genetics: Methods and Protocols, eds R. C. Elston, J. M. Satagopan, and S. Sun (New York, NY: Humana Press; Springer), 263-284.

Sebat, J., Lakshmi, B., Troge, J., Alexander, J., Young, J., Lundin, P., et al. (2004). Large-scale copy number polymorphism in the human genome. Science 305, 525-528. doi: 10.1126/science.1098918

Sergeant, D. (1969). Experimental investigation of absolute pitch. J. Res. Music Educ. 17, 135-143. doi: 10.2307/3344200

Singleton, A. B. (2011). Exome sequencing: a transformative technology. Lancet Neurol. 10, 942-946. doi: 10.1016/S1474-4422(11)70196-X

Sohn, H.-M. (1999). The Korean Language. Cambridge: Cambridge University Press.

Spencer, C. C. A., Su, Z., Donnelly, P., and Marchini, J. (2009). Designing genomewide association studies: sample size, power, imputation, and the choice of genotyping chip. PLoS Genet. 5:e1000477. doi: 10.1371/journal.pgen.1000477

Stein, E., and Tessier-Lavigne, M. (2001). Hierarchical organization of guidance receptors: silencing of netrin attraction by slit through a Robo/DCC receptor complex. Science 291, 1928-1938. doi: 10.1126/science. 1058445

Strachan, T., and Read, A. P. (1999). "Complex diseases: theory and results," in Human Molecular Genetics, 2nd Edn. New York, NY: Wiley-Liss.

Stranger, B. E., Forrest, M. S., Dunning, M., Ingle, C. E., Beazley, C., Thorne, N., et al. (2007). Relative impact of nucleotide and copy number variation on gene expression phenotypes. Science 315, 848-853. doi: 10.1126/science.1136678

Stranger, B. E., Stahl, E. A., and Raj, T. (2011). Progress and promise of genomewide association studies for human complex trait genetics. Genetics 187, 367-383. doi: 10.1534/genetics.110.120907

Sun, L., and Dimitromanolakis, A. (2012). "Identifying cryptic relationships," in Statistical Human Genetics: Methods and Protocols, eds R. C. Elston, J. M. Satagopan, and S. Sun (New York, NY: Humana Press; Springer), 47-58.

Sweatt, J. (2013). The emerging field of neuroepigenetics. Neuron 80, 624-632. doi: 10.1016/j.neuron.2013.10.023

Szalontai, A., and Csiszar, K. (2013). Genetic insights into the functional elements of language. Hum. Genet. 132, 959-986. doi: 10.1007/s00439-013-1317-0

Teo, S. M., Pawitan, Y., Ku, C. S., Chia, K. S., and Salim, A. (2012). Statistical challenges associated with detecting copy number variations with next-generation sequencing. Bioinformatics 28, 2711-2718. doi: 10.1093/bioinformatics/bts535

Theusch, E., Basu, A., and Gitschier, J. (2009). Genome-wide study of families with absolute pitch reveals linkage to $8 \mathrm{q} 24.21$ and locus heterogeneity. Am. J. Hum. Genet. 85, 112-119. doi: 10.1016/j.ajhg.2009.06.010

Theusch, E., and Gitschier, J. (2011). Absolute pitch twin study and segregation analysis. Twin Res. Hum. Genet. 14, 173-178. doi: 10.1375/twin.14.2.173

Torii, M., Hackett, T. A., Rakic, P., Levitt, P., and Polley, D. B. (2013). EphA signaling impacts development of topographic connectivity in auditory corticofugal systems. Cereb. Cortex 23, 775-785. doi: 10.1093/cercor/bhs066

Trainor, L. J., and Heinmiller, B. M. (1998). The development of evaluative responses to music: infants prefer to listen to consonance over dissonance. Infant Behav. Dev. 21, 77-88. doi: 10.1016/S0163-6383(98)90055-8

Trainor, L. J., and Trehub, S. E. (1992). A comparison of infants' and adults' sensitivity to Western musical structure. J. Exp. Psychol. Hum. Percept. Perform. 18, 394-402. doi: 10.1037/0096-1523.18.2.394

Trainor, L. J., and Trehub, S. E. (1993). What mediates infants' and adults' superior processing of the major over the augmented triad? Music Percept. 11, 185-196. doi: $10.2307 / 40285615$

Trainor, L. J., Tsang, C. D., and Cheung, V. H. W. (2002). Preference for sensory consonance in 2- and 4-month-old infants. Music Percept. 20, 187-194. doi: $10.1525 / \mathrm{mp} .2002 .20 .2 .187$

Trehub, S. E. (2003). The developmental origins of musicality. Nat. Neurosci. 6, 669-673. doi: 10.1038/nn1084

Trehub, S. E. (2006). "Infants as musical connoisseurs," in The Child as Musician: A Handbook of Musical Development, ed G. E. McPherson (New York, NY: Oxford University Press), 33-49. doi: 10.1093/acprof:oso/9780198530329.003.0002

Trehub, S. E., Bull, D., and Thorpe, L. A. (1984). Infants' perception of melodies: the role of melodic contour. Child Dev. 55, 821-830. doi: 10.2307/1130133

Trehub, S. E., Schellenberg, E. G., and Kamenetsky, S. B. (1999). Infants' and adults' perception of scale structure. J. Exp. Psychol. Hum. Percept. Perform. 25, 965-975. doi: 10.1037/0096-1523.25.4.965

Trehub, S. E., Thorpe, L. A., and Morrongiello, B. A. (1987). Organizational processes in infants' perception of auditory patterns. Child Dev. 58, 741-749. doi: $10.2307 / 1130211$
Ukkola, L. T., Onkamo, P., Raijas, P., Karma, K., and Järvelä, I. (2009). Musical aptitude is associated with AVPR1A-haplotypes. PLoS ONE 4:e5534. doi: 10.1371/journal.pone.0005534

Ukkola-Vuoti, L., Kanduri, C., Oikkonen, J., Buck, G., Blancher, C., Raijas, P., et al. (2013). Genome-wide copy number variation analysis in extended families and unrelated individuals characterized for musical aptitude and creativity in music. PLoS ONE 8:e56356. doi: 10.1371/journal.pone.0056356

Ukkola-Vuoti, L., Oikkonen, J., Onkamo, P., Karma, K., Raijas, P., and Järvelä, I. (2011). Association of the arginine vasopressin receptor 1A (AVPR1A) haplotypes with listening to music. J. Hum. Genet. 56, 324-329. doi: 10.1038/jhg.2011.13

Verweij, K. J. H., Mosing, M. A., Zietsch, B. P., and Medland, S. E. (2012). "Estimating heritability from twin studies," in Statistical Human Genetics: Methods and Protocols, eds R. C. Elston, J. M. Satagopan, and S. Sun (New York, NY: Humana Press; Springer), 151-170.

Vinkhuyzen, A. A. E., Van Der Sluis, S., De Geus, E. J. C., Boomsma, D. I., and Posthuma, D. (2010). Genetic influences on "environmental" factors. Genes Brain Behav. 9, 276-287. doi: 10.1111/j.1601-183X.2009.00554.X

Vinkhuyzen, A. A. E., Van Der Sluis, S., Posthuma, D., and Boomsma, D. I. (2009) The heritability of aptitude and exceptional talent across different domains in adolescents and young adults. Behav. Genet. 39, 380-392. doi: 10.1007/s10519009-9260-5

Visscher, P. M., Hill, W. G., and Wray, N. R. (2008). Heritability in the genomics era-concepts and misconceptions. Nat. Rev. Genet. 9, 255-266. doi: 10.1038/ $\operatorname{nrg} 2322$

Wain, L. V., Armour, J. A., and Tobin, M. D. (2009). Genomic copy number variation, human health, and disease. Lancet 374, 340-350. doi: 10.1016/S01406736(09)60249-X

Watts, C., Murphy, J., and Barnes-Burroughs, K. (2003). Pitch matching accuracy of trained singers, untrained subjects with talented singing voices, and untrained subjects with nontalented singing voices in conditions of varying feedback. J. Voice 17, 185-194. doi: 10.1016/S0892-1997(03)00023-7

Weeks, D. E., Lehner, T., Squires-Wheeler, E., Kaufmann, C., and Ott, J. (1990). Measuring the inflation of the LOD score due to its maximization over model parameter values in human linkage analysis. Genet. Epidemiol. 7, 237-243. doi: 10.1002/gepi.1370070402

Welch, G. F. (2006). "Singing and vocal development," in The Child as Musician: A Handbook of Musical Development, ed G. E. McPherson (Oxford: Oxford University Press), 311-329. doi: 10.1093/acprof:oso/9780198530329. 003.0016

Wilson, S. J., Lusher, D., Martin, C. L., Rayner, G., and McLachlan, N. (2012). Intersecting factors lead to absolute pitch acquisition that is maintained in a "fixed do" environment. Music Percept. 29, 285-296. doi: 10.1525/mp.2012.29.3.285

Wilson, S. J., Lusher, D., Wan, C. Y., Dudgeon, P., and Reutens, D. C. (2009). The neurocognitive components of pitch processing: insights from absolute pitch. Cereb. Cortex 19, 724-732. doi: 10.1093/cercor/bhn121

Winkler, I., Háden, G. P., Ladinig, O., Sziller, I., and Honing, H. (2009). Newborn infants detect the beat in music. Proc. Natl. Acad. Sci. U.S.A. 106, 2468-2471. doi: 10.1073/pnas.0809035106

Wong, S. T., Athos, J., Figueroa, X. A., Pineda, V. V., Schaefer, M. L., Chavkin, C. C., et al. (1999). Calcium-stimulated adenylyl cyclase activity is critical for hippocampus-dependent long-term memory and late phase LTP. Neuron 23, 787-798. doi: 10.1016/S0896-6273(01)80036-2

Xu, W., Bull, S. B., Mirea, L., and Greenwood, C. M. T. (2012). "Model-free linkage analysis of a binary trait," in Statistical Human Genetics: Methods and Protocols, eds R. C. Elston, J. M. Satagopan, and S. Sun (New York, NY: Humana Press; Springer), 317-345.

Yao, Y. C., and Tai, J. J. (2000). Bias correction for segregation ratio estimation in human genetics. Biometrics 56, 795-800. doi: 10.1111/j.0006341X.2000.00795.x

Zatorre, R. J. (2003). Absolute pitch: a model for understanding the influence of genes and development on neural and cognitive function. Nat. Neurosci. 6, 692-695. doi: 10.1038/nn1085

Zatorre, R. J., Delhommeau, K., and Zarate, J. M. (2012). Modulation of auditory cortex response to pitch variation following training with microtonal melodies. Front. Psychol. 3:544. doi: 10.3389/fpsyg.2012.00544

Zentner, M. R., and Kagan, J. (1996). Perception of music by infants. Nature 383, 29. doi: $10.1038 / 383029 \mathrm{a} 0$ 
Zhong, S., Israel, S., Xue, H., Sham, P. C., Ebstein, R. P., and Chew, S. H. (2009). A neurochemical approach to valuation sensitivity over gains and losses. Proc. $R$. Soc. B Biol. Sci. 276, 4181-4188. doi: 10.1098/rspb.2009.1312

Conflict of Interest Statement: The authors declare that the research was conducted in the absence of any commercial or financial relationships that could be construed as a potential conflict of interest.

Received: 24 December 2013; accepted: 08 June 2014; published online: 27 June 2014. Citation: Tan YT, McPherson GE, Peretz I, Berkovic SF and Wilson SJ (2014) The genetic basis of music ability. Front. Psychol. 5:658. doi: 10.3389/fpsyg.2014.00658

This article was submitted to Auditory Cognitive Neuroscience, a section of the journal Frontiers in Psychology.

Copyright (C) 2014 Tan, McPherson, Peretz, Berkovic and Wilson. This is an openaccess article distributed under the terms of the Creative Commons Attribution License (CC BY). The use, distribution or reproduction in other forums is permitted, provided the original author(s) or licensor are credited and that the original publication in this journal is cited, in accordance with accepted academic practice. No use, distribution or reproduction is permitted which does not comply with these terms. 